\title{
REVIEW
}

\section{Personalized chronobiologic cybercare; other chronomics' progress by transdisciplinary cycles' congruences: season's appreciations 2009}

\author{
Franz Halberg ${ }^{1}$, Germaine Cornélissen ${ }^{1}$, Patricia Grambsch ${ }^{2}$, Rollin McCraty ${ }^{3}$, Larry Beaty ${ }^{1}$, \\ Jarmila Siegelová ${ }^{4}$, Pavel Homolka ${ }^{4}$, Dewayne Carol Hillman ${ }^{1}$, Judy Finley ${ }^{1}$, Faithe Thomas ${ }^{1}$, \\ Tomoshige Kino $^{5}$, Miguel Revilla ${ }^{6}$, Othild Schwartzkopff ${ }^{1}$ \\ ${ }^{1}$ Halberg Chronobiology Center and ${ }^{2}$ Department of Biostatistics, University of Minnesota, Minneapolis, MN, USA; \\ ${ }^{3}$ Institute of HeartMath, Boulder Creek, CA, USA; ${ }^{4}$ Department of Functional Diagnostics and Rehabilitation, St. Anna Teaching \\ Hospital, Masaryk University, Brno, Czech Republic; ${ }^{5}$ Unit on Molecular Hormone Action, Program in Reproductive and Adult \\ Endocrinology, Eunice Kennedy Shriver National Institute of Child Health and Human Development, National Institutes of \\ Health, Bethesda, MD, USA; ${ }^{6}$ Department of Applied Mathematics, University of Valladolid, Spain
}

Written originally by Franz Halberg in response to an invitation by the Committee of Senior Physiologists of the American Physiological Society.

Received $19^{\text {th }}$ March 2010.

Revised $30^{\text {th }}$ June 2010.

Published online $2^{\text {nd }}$ July 2010.

\begin{abstract}
Summary
Originally a remembrance of an elderly physiologist, this paper illustrates the need for a standardized specification of certain experimental or survey conditions beyond those usually necessarily disclosed in conventional publications, namely calendar-dates, clock-times and geographic locations, to allow reference to helio-ionosphero-geomagnetics along with natural and artificial lighting and temperature. When possible, body times given by a marker rhythm also should be specified. A personalized chronobiologic cybercare can eventually include focus on infradians, beyond circadians. Benefits from longitudinal monitoring are:

1. Chronobiologically-interpreted blood pressure (BP) and heart rate (HR) monitoring enables the diagnosis and treatment of vascular variability anomalies (VVAs) or, if lasting in several 7-day records, disorders (VVDs), not yet screened for in practice, that increase cardiovascular disease risk independently of an elevated BP. 2. The optimal treatment time for the individual patient can be determined and potential harm avoided, since the same dose of the same medication for the same patient can help or harm depending only on when it is administered. 3. Benefit may be derived in cancer treatment timed according to marker rhythmometry. 4. The change from a spotcheck-based health care to one of internet-aided systematic self-surveillance by the automatic collection and analysis of time series stems from evidence that nonphotic and photic environmental influences affect biota, associations that may depend on geographic and temporal location. 5. Imaging in time includes formatting for time, globally and locally, for the mapping of a transdisciplinary spectrum of cycles involving "good" and "bad" strain in human physiology,versus sudden cardiac death, suicide and terrorism, all latter requiring rational countermeasures.
\end{abstract}

Key words: blood pressure; cancer; death; heart rate; time; nonphotic cycles; suicide; terrorism; vascular variability disorders (VVDs)

Dedicated to the memories of Dr. Julius Halberg, the senior author's father; Profs. Howard Levine and Frederic C. Bartter, friends and associates in research; and the most hospitable Arkady Blank.

Franz Halberg, Halberg Chronobiology Center, University of Minnesota, MMC 8609, 420 Delaware Street SE, Minneapolis, MN 55455, USA
halbe001@umn.edu
612-624-6976
具 $612-624-9989$ 


\section{INTRODUCTION}

All matter, organic or inorganic, changes with time in vitro and notably in vivo (Halberg 1969). This time structure (chronome) is normally within the very range of currently acceptable organismic and environmental variability, where the quality of not being too high or too low does not necessarily imply randomness or normalcy. Table 1 summarizes what we learned in the past 65 years about happenings within the limits of values that are normal only by being neither too high nor too low, values which one can call those of everyday ecology, including Thomas Kenner's (2009) everyday physiology. In a system open to its environment, such as an organism, everybody's functions also vary with everyday environmental change.

At the peak of his career, the adult Claude Bernard recognized as one of his major discoveries the finding of the "extreme [and we add informative] variability of the internal environment" (Bernard 1865). We are that Bernard's students, rather than followers of the elderly Bernard who wrote about relative constancy. In the biosphere, we map chronomes, consisting of deterministic and other chaos, trends and a spectrum of rhythms, with periods $(\tau \mathrm{s})$ ranging from fractions of a second to millions of years, some already partly mapped (Halberg et al. $2009 \mathrm{~d})$. These $\tau \mathrm{s}$, required for the study of mechanisms underlying the changes in organic and inorganic matter, also constitute indispensable control information in its own right. One of us $(\mathrm{FH})$ dubbed this microscopy in time "Chronobiology" in a Current Contents Citation Classic (Halberg 1969). He developed methods for its study since 1948, including by 1958 the finding that RNA formation preceded DNA synthesis (Halberg et al. 1958), before the findings of a not so "inverse" transcriptase (Harman and Dietrich 2008). He also published that both RNA and DNA formation are circadian periodic, then a big surprise (Halberg et al. 2003). Others failed to recognize the degree of generality of rhythms and in correspondence (probably not intended for publication) opposed a scientific branch sui generis (Cambrosio and Keating 1983).

\section{MERITS OF CHRONOME-BASED INDIVIDUALIZED DIAGNOSIS AND THERAPY: CYBERCARE}

The issue revolves around homeostasis, Table 1, used unknowingly by the vast majority of physiologists as a tacit excuse for drawing a curtain of ignorance over the normal range, thereby losing an oftenindispensable control information. Too often, an imaginary "baseLINE" is a single sample before the start of a study, and without any awareness and thus without consideration of the variability that may occur more or less spontaneously within some imaginary lower and upper limits - as Cannon's hunting, or if it occurs over longer time spans, as "secular variation". Eventually, vascular variability disorders (VVDs) were found, such as an overswing of BP, which even when the average pressure is within the acceptable range, can represent a risk greater than that of a BP elevation (Halberg et al. 2009b). This concerns the very many millions of people treated for hypertension, where the use of hypotensive drugs may trade, for the lowering of a high BP (a VVD in itself) another VVD (Halberg et al. 2006a, b, 2009b, d, Watanabe et al. 2008), such as a circadian overswing (CHAT, short for Circadian Hyper-Amplitude-Tension) associated with a greater risk of stroke than a high BP (Fig. 15, sections IIA-C in Halberg et al. 2006b).

\section{ELEVATED PULSE PRESSURE IN 7-DAY RECORDS OUTDOES MORTALITY WITH AGE}

The interim results of the team of two of us (JS and $\mathrm{PH}$ ) in Fig. 1A show a race among VVDs, with a relatively small sample of systematically monitored 7-day series of BP and HR. All VVDs are associated with a point estimate of relative risk larger than unity and approach significance at the $5 \%$ probability level, but only one VVD, a pulse pressure greater than $60 \mathrm{mmHg}$ (not assessed in Otsuka et al. 1996, cf. Halberg et al. 2006a, b, Cornélissen et al. 2008a), has a relative risk statistically significantly larger than unity. This small sample awaits further scrutiny and comparisons with other ethnic groups. Some other VVDs ("systolic or diastolic MESOR- hypertension" and "systolic and diastolic CHAT") represent a life-threatening risk about as great as age in Europeans. This result is in keeping with the statistically significant results obtained on Japanese, Fig. 1B (Cornélissen et al. 2008a), and Taiwanese.

VVDs remain the immediate clinical challenge for prehabilitation, that is for picking up high cardiovascular disease risks in the population at large in order to treat patients in appropriate clinical trials. The population needed for this purpose may be estimated from results on Caucasians in Fig. 1A, on Asians in Fig. 1B and in a consensus document (see Figs 10 and 14 in Halberg et al. 2009b). 
Table I: Chronobiological and chronomic concepts, tools and long-term goals. Time structures (chronomes) around us are aligned with chronomes in us, by chronomics (figurative telescopy in time), complementing chronobiology, the study of the mechanisms and applications of biological chronomes, complementary to genomes, a figurative microscopy in time (Halberg et al. 2001d). ${ }^{1}$

\begin{tabular}{|c|c|c|c|}
\hline View of: & $\begin{array}{l}\text { I. Current homeostatic } \\
\text { response physiology }\end{array}$ & $\begin{array}{l}\text { II. Time-structural (chronome) } \\
\text { physiology }\end{array}$ & Utility of II \\
\hline $\begin{array}{l}\text { 1. Definition of normalcy, e.g., } \\
\text { health }\end{array}$ & $\begin{array}{l}\text { Negative: absence of } \\
\text { abnormality, e.g. of disease } \\
\{1,2\} \text {. Curtain of ignorance on } \\
\text { everyday physiology outside } \\
\text { the normal range of reference } \\
\text { values }\end{array}$ & $\begin{array}{l}\text { Positive: parametric and } \\
\text { non-parametric assessment. } \\
\text { Alteration in the normal range } \\
\text { will be detected }\end{array}$ & $\begin{array}{l}\text { Time structural (chronomic } \\
\text { endpoints): the control in } \\
\text { whatever we do }\{3\}\end{array}$ \\
\hline $\begin{array}{l}\text { 2. Quantification of normalcy, } \\
\text { e.g., health }\end{array}$ & $\begin{array}{l}\text { Population-based: percent } \\
\text { abnormality, e.g., morbidity } \\
\text { and mortality }\end{array}$ & $\begin{array}{l}\text { Individualized: P-values for } \\
\text { statistical significance and for } \\
\text { scientific (i.e., clinical) } \\
\text { signification }\end{array}$ & $\begin{array}{l}\text { Strain assessment and } \\
\text { recognition of risk of } \\
\text { abnormality before the fait } \\
\text { accompli of catastrophe }\end{array}$ \\
\hline 3. Interpretation of reality & $\begin{array}{l}\text { Putative (imaginary) set points, } \\
\text { e.g., the fiction of a true } \\
\text { time-invariant blood pressure }\end{array}$ & $\begin{array}{l}\text { Chronomes: consisting of } \\
\text { a) rhythms; } \\
\text { b) trends; } \\
\text { c) deterministic and other } \\
\text { chaos; } \\
\text { d) any residuals and } \\
\text { interactions among a, b, c } \\
\text { and d }\end{array}$ & $\begin{array}{l}\text { Chronorisk syndromes: } \\
\text { 1) circadian overswinging of } \\
\text { blood pressure; or } \\
\text { 2) chronome alteration with } \\
\text { heart rate jitter deficit; or } \\
\text { 3) circadian vascular rhythm } \\
\text { alteration; or } \\
\text { 4) altered about-yearly rhythms } \\
\text { in circulating prolactin and } \\
\text { TSH signaling breast and } \\
\text { prostatic cancer risk elevation }\end{array}$ \\
\hline 4. Variability & Confounder (foe) & $\begin{array}{l}\text { Of interest in its own right } \\
\text { (friend) }\end{array}$ & $\begin{array}{l}\text { Tool and invaluable source of } \\
\text { much information }\{4\}\end{array}$ \\
\hline $\begin{array}{l}\text { 5. Biosystems' behavior if } \\
\text { perturbed }\end{array}$ & $\begin{array}{l}\text { Settling down to an imaginary } \\
\text { steady state (constancy) or } \\
\text { limited random 'hunting', e.g., } \\
\text { as (mistakenly anticipated) } \\
\text { when a single blood pressure is } \\
\text { taken after some ( } \leq 30) \\
\text { minutes of rest }\end{array}$ & $\begin{array}{l}\text { Dynamic chronomes that } \\
\text { characterize health within } \\
\text { chronobiologic limits set by the } \\
\text { intermodulation of the } \\
\text { chronomes' } \alpha-, \beta-, \gamma \text { - and } \delta \text { - } \\
\text { (spontaneous, reactive and } \\
\text { modulating) rhythms (Halberg } \\
\text { et al. 2000), e.g., a large } \\
\text { circadian change in blood } \\
\text { pressure during bed rest }\end{array}$ & $\begin{array}{l}\text { Positive individualized } \\
\text { quantification of health }\end{array}$ \\
\hline 6. Analogy & $\begin{array}{l}\text { Thermostats with "hunting" } \\
\text { noise (information lost) }\end{array}$ & $\begin{array}{l}\text { Pendulums in resolvable } \\
\text { chronomes }\end{array}$ & Prediction from parameters \\
\hline $\begin{array}{l}\text { 7. Physiologic or normal } \\
\text { ranges of variation }\end{array}$ & $\begin{array}{l}\text { Broad, random, indivisible; } \\
\text { equated to noise, neglecting } \\
\text { use for diagnosis and treatment }\end{array}$ & $\begin{array}{l}\text { Structured, predictable }\{5\} ; \\
\text { resolved into reference ranges } \\
\text { (chronodesms) for chronomes }\end{array}$ & $\begin{array}{l}\text { Circadian blood pressure } \\
\text { amplitude (BP-A) or circadian } \\
\text { standard deviation (SD) for } \\
\text { detecting effect of in utero } \\
\text { exposure to betamimetics }\end{array}$ \\
\hline 8. Action? & $\begin{array}{l}\text { None: confounder; } \\
\text { incompatible with detection of } \\
\text { circadian blood pressure } \\
\text { disorder }\end{array}$ & $\begin{array}{l}\text { Monitoring and as-one-goes } \\
\text { analyses, and on this basis, } \\
\text { action (Bittle et al. 1985, } \\
\text { Cornélissen et al. 1993, Itoh et } \\
\text { al. 1994) }\end{array}$ & $\begin{array}{l}\text { Detects treatable overswinging } \\
\text { of BP-A, which carries a } 720 \% \\
\text { increase in risk of ischemic } \\
\text { stroke; improves cancer } \\
\text { treatment }\end{array}$ \\
\hline
\end{tabular}


9. Endpoints

10. Sources of variation

11. Mechanism

12. Hierarchy

13. Teleonomy

14. Relation to evolution

15. Biological evolution

16. Health and environmental care

17. Animal husbandry, apiculture, aquaculture and economic entomology

18. Value

\author{
- Original values: \\ Casual measurements at times \\ of convenience, not necessarily \\ of pertinence (e.g., of 'the' \\ blood pressure with $>40 \%$ \\ uncertainty in diagnosis in \\ cases of borderline \\ hypertension) (Halberg and \\ Cornélissen 1995): \\ Time-unspecified: \\ mean
}

Exogenous responses to stimuli from proximity mostly from the habitat niche

Feedbacks along axes unstructured 'modulation' like the deus ex machina in a physiological tragedy since outcomes may be unpredictable

Up/down

Righting and regulation

Cyclicity as such ignored

Darwinian, externally adaptive

Medical treatment often limited and late, given mostly after the diagnosis of overt disease $\{7\}$

Timed by convenience

Often wasteful
Time-specified chrones in chronomes:

Time-coded:

- original values

- SD

- MESOR(s)

- $\operatorname{period}(\mathrm{s}), \tau$

- amplitude(s), A

- acrophase(s), $\Phi$

- waveform(s) (A, $\Phi)$ pairs of

harmonics

- trends

- chaotic dimensions

- residuals

Endogenous and exogenous; responses to stimuli from near and far, including cosmos

Feedsidewards in networks with alternating outcomes: predictable (insofar as rhythmic) as a chronomodulation

Collateral:

alternating primacy among intermodulating

multifrequency rhythms in chronomes

Anticipatory, preparatory coordination

Omnis cyclus biologicus e cyclo cosmico praeterito vel praesenti (all cycles from cosmic cyclicity past or present)

More and more internal and integrative while externally adaptive to both past and present nature and nurture

Optimization according to marker chronomes (of interventions by drugs and/or devices, e.g., pacemakers, with diagnosis and treatment refined by narrowed reference range and assessment within that range of chronorisk leading to preventive treatment timed by marker rhythms (that also serve to validate effect)

Chronome-based

Optimization: greater efficacy; fewer undesirable effects

Waste reduced

Chronobiologic software: - provides information, e.g., on points 3 and 4 above - guides timed treatment that has greatly prolonged the survival of cancer patients

Resolution of impact of storms in space on myocardial infarctions on earth: space weather report? $\{6\}$

Predictable since rhythmic neuro-endocrine-vascular intermodulations can account for outcomes that may be as different as stimulation vs. inhibition of immunity

Focusing on selected tasks at different times

Greater flexibility

Seeks origins of life inseparably from origins of cosmos

Instrumented self-help to monitor space weather to learn how external cycles entered genes

E.g., catastrophic and iatrogenic disease prevention

Cost-effective 
19. Seeking inanimate and animate origins

20. Life in the scheme of physical and cultural things

21. Cosmos

22. Investigator satisfaction
Stratigraphy for identifying, in geological space, sequences in time; radiocarbon dating

Survival of the fittest with humans dominating food chains viewed in the perspective of bioenergetics in a mostly terrestrial ecology
Additional tracing of chronomo-ontogeny and chronomo-phylogeny $\{8\}$ in the context of glimpses of cycles in corresponding spans of a figurative cosmo-ontogeny (Halberg et al. 2004b)

Physically and socially chronomodulating and thus informatively and integratively evolving biota molded by human culture Homo not only faber but cosmoinformans and chronomodulans in a budding broad chrono-cosmoecology (Halberg et al. 2004a)
Adds to knowledge of the past to better optimize the future

Humans safeguard the integrity of the biosphere as it extends into the cosmos and as we speculatively, by joining the approaches by ablations, superposed epochs and resonance tests concomitantly explore the temporal aspects of our origins, possibly represented by our chronomes that in turn may reflect a long-past environment (Cornélissen et al. 2002, Halberg et al. 2008d)

Survival from hard vascular events of individuals and from war and diseases of societies of populations (Cornélissen et al. 2002, Halberg et al. 2008d)
The broad spectrum of non-photic environmental cycles, reflected in physiology, pathology and sociology (including politics and militarism), as in the $\sim 30$-year BEL cycle (Halberg et al. 2008b, 2009a), Figs 2-5

Sheer fun: long-standing controversy is resolved by accounting for both the genetic and broadly environmental bases of the feedsidewards among inanimate and animate cycles that constitute life; disease risk recognition promises to lead to the prevention or timed treatment of catastrophic diseases such as stroke, cancer or sudden death

${ }^{1}$ Numbers in \{\} indicate endnotes.

$\{1\}$ Just as contemporary physics, by fission and fusion, gathers more and more energy by splitting the atom, biomedicine gathers more and more information by splitting the normal value range into time structures, thereby resolving, e.g., trends and chaos as well as rhythms (fission) and looking at their feedsideward interrelations (fusion) for a better understanding of an interdigitated, indivisible Janus-faced inseparable soma and psyche.

$\{2\}$ Health care, required to deal with disease risk gauged within the normal range, such as conditions in Fig. 1, will be missed by current health promotion, a step in the right direction, by its recommendations of attention to diet, exercise or relaxation, but should be preceded and followed by a chronobiological assessment of the timing as well as effect of recommended procedures, rather than merely by the current reliance of ruling out the occurrence of values outside the normal range.

$\{3\}$ Location and dispersion indices include the determination from histogram of values, of means (arithmetic, geometric, harmonic), median, mode, minimum, maximum, 100\% and 90\% ranges, interquartile range, standard deviation (SD), weighted SD, standard error (SE); these endpoints are computed from time-unspecified values in the context of the homeostatic approach, whereas in the chronobiologic framework the location and dispersion indices are used as such on systematic time-specified samples, as time series-derived parameters, i.e., on each of the endpoints of time structures, $M, A, \Phi,\left(A_{n}, \Phi_{n}\right)$, etc.

$\{4\}$ An international project on The Biosphere and the Cosmos, BIOCOS, focuses first upon chronocardiology in general and blood pressure and heart rate dynamics in particular, for stroke and other catastrophic vascular disease prevention (consult chronobiology home page, http://www.msi.umn.edu/ halberg/).

$\{5\}$ Information from the physiologic range for prevention, diagnosis or treatment is much refined when this range is individualized and interpreted in the light of a personalized background as well as in the context of gender-, age-, ethnicity- and chronome stage-specification.

$\{6\}$ The need for forecasting storms in space should be explored further on the basis of systematic studies aligning physiological lifetime monitoring and clinical and archival statistical studies with ongoing physical data collection near and far, both for ascertaining effects and in 
studying countermeasures. Blood pressure, heart rate and other physiological and psychological monitoring would also provide basic information on any cross-spectral and other associations (feedsidewards; Halberg et al. 2000) within and among biological and environmental chronomes while further providing reference values of medical interest.

$\{7\}$ Even if some preventive measures have also been long implemented, e.g., by vaccination, and even if recently more and more hygienic measures (such as exercise and caloric, fat and sodium restriction) are also popular, all can be greatly improved by timing designed with chronobiological individualization. Current action based on group results fails to recognize, for instance, that the blood pressure response to salt (Bittle et al. 1985, Cornélissen et al. 1993, Itoh et al. 1994) may differ as a function of circadian stage, and there are indeed individuals in whom the addition of salt lowers rather than raises blood pressure (Bittle et al. 1985, Cornélissen et al. 1993).

\{8\} Development from the egg of rhythms (some may be much older than shards) and of other constituents of chronomes to trace their homeoor heterochronically roughly 'recapitulatory' development across species, with both ontogeny and phylogeny, perhaps tracing in their turn the concomitant development of the geocosmic environment. This distant basic goal can be pursued with the immediate reward of obtaining indispensable reference values for the diagnosis of two chronobiologic risk syndromes, circadian hyper-amplitude-tension, briefly CHAT, and chronome alterations of heart rate variability, briefly CAHRVs, just as an extreme deficit in heart rate jitter is associated with an increase in the risk of ischemic stroke or of a myocardial infarction of 720 and $550 \%$, respectively.

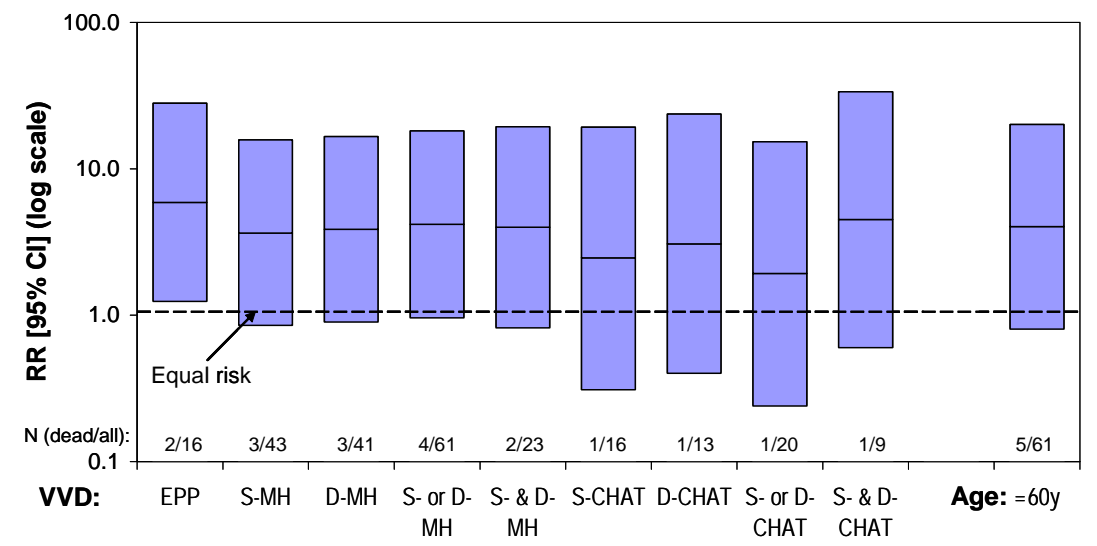

Fig. 1A. Among vascular variability disorders (VVDs) assessed from 7-day ambulatory monitoring, and as compared to age, an excessive pulse pressure carries the largest cardiovascular mortality risk ( 7 deaths among 252 subjects). RR: relative risk, defined as $\mathrm{RR}=$ (number of deaths with a VVD/number of cases with a VVD)/(number of deaths without a VVD/number of cases without a VVD), EPP: excessive pulse pressure (PP>60 mmHg), MH: MESOR-hypertension (S: systolic, D: diastolic), CHAT: circadian hyper-amplitude-tension, CI: $95 \%$ confidence interval. For comparison, only subjects $\geq 50$ years are considered, as earliest death occurred at age 50. Original data of Siegelová J, Homolka P, Fišer B and Dušek J. Interim results presented to prompt clinical treatment trials of VVDs.

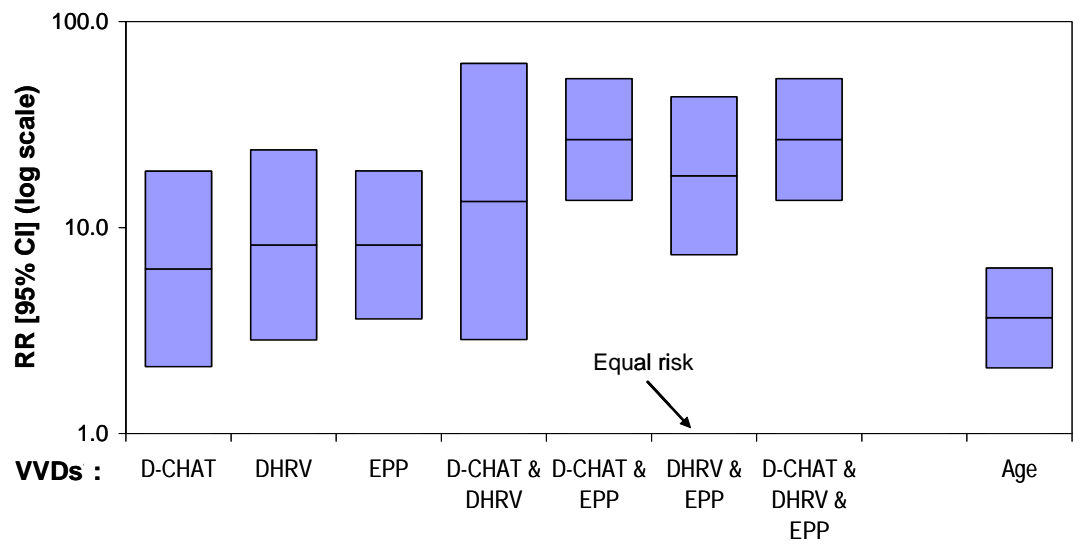

Fig. 1B. Among vascular variability disorders (VVDs) in Asians (Cornélissen et al. 2008a) and as compared to age, excessive pulse pressure (EPP; $\mathrm{PP}>60 \mathrm{mmHg}$ ), diastolic circadian hyper-amplitude-tension (D-CHAT), and deficient heart rate variability (DHRV; HR-SD $<7.5$ beats/min) carry a large cardiovascular disease risk. RR: relative risk, defined as $\mathrm{RR}=$ (number of events with a VVD/number of cases with a VVD)/(number of events without a VVD/number of cases without a VVD), where "event" stands for adverse outcome, CI: 95\% confidence interval. Original data of Kuniaki Otsuka. 
Earlier work based on spotchecks suggested that pulse pressure is a strong risk factor for coronary events in untreated hypertensive men, whereas stroke is best prevented by mean BP (Millar et al. 1999).

\section{COSMIC BIOSPHERIC ASSOCIATIONS GAUGED BY CONGRUENCE OF RECIPROCAL PERIODS, $\tau \mathrm{s}$}

By 1991, we were long engaged in aligning more and more chronomes of the environment with those in living matter (Halberg et al. 1991), analyzing associations among them, an endeavor known as "Chronomics" (Halberg 2000, Halberg et al. 2001d). At the time of this writing, the point estimate of a cycle's $\tau$ in FH's systolic BP is about $(\sim) 11$ years, while that in his diastolic BP is $\sim 15$ years and in his HR $\sim 30$ years. The "conservative" ordering CIs (95\% confidence intervals) (Marquardt 1963) of the $\tau$ s do not overlap each other. This non-overlap is so great that it may mean a true difference, whether or not the CIs are very much wider. It is true that the assumptions for computing CIs often are not met, and we use CIs for ordering purposes only. Fortuitously perhaps, the cycles found objectively in FH's three sets of data each correspond in length to a different solar activity cycle, namely to the decadal Horrebow (Thiele 1859)-Schwabe (1844) cycle in relative sunspot numbers, Makarov and Sivaraman's (1989) global solar cycle, and the Brückner (1890, cf. Stehr and von Storch 2000, Halberg et al. 2009c)-Egeson (1889)-Lockyer (1901) climate cycle (dubbed BEL) found in changes of the length in the sunspot cycle.

It may also be happenstance that the BEL cycle is reflected in our analyses of 2,556 years of international battles (Wheeler 1951), in hundreds of years of military political affairs (Chizhevsky 1971), and of economics (Goldstein 1988), as well as in health and disease (Halberg et al. 2008d), where we also find a whole spectrum of new cycles known in physics, such as $\sim 16$-month and $\sim 5$-month cycles reflected further in sudden cardiac death (Halberg et al. 2006a, b) and in cardiac arrhythmia (Cornélissen et al. 2007). The fact that there are often environmental counterparts to cycles in biology and physiology (as in the case of FH's data) is an argument supporting the validity of the three different $\tau$ s found in the same circulation. Happenstance is not ruled out, but it can be rendered unlikely by a statistical significance test of congruence just developed by one of us (PG).

Beyond associations gauged by congruence in $\tau$, defined by overlapping if not overlying CIs of the reciprocal cosmic-biospheric $\tau \mathrm{s}$, there can also be acongruence in phase, congruence in $\tau$ notwithstanding, Figs 2 and 3, a challenging topic in its own right. Partial congruence, i.e., different time courses of phases of 4 variables, Figs $2 \mathrm{~A}$ to $2 \mathrm{C}$, with global congruence of $\tau \mathrm{s}$, the latter not shown, supports the requirement that a complete description of aeolian behavior involves both global and time-varying analyses. We can also let the cosmos do a remove and/or replace approach, to find that the $\sim 16$-month cycle in FH's systolic BP is dampened when the solar wind loses that component or buries it in noise so that it is no longer detectable (Halberg et al. 2006a). We also find in 39 years of terrorism no yearly component but a $\sim 16$-month component that appears intermittently in solar wind speed and in geomagnetism. Its appearance, defined by gaining statistical significance, happens to be followed with a lag by the same component's amplification in terrorism, where this cycle lasts for a long time after the triggering and driving environmental $\sim 16$-month component has lost statistical significance (Halberg et al. 2008d), Figs 3A and 3B. Fig. 4 shows physiological associations with solar activity for the case of 7-day rhythms in HR (Cornélissen et al. 1996), complementing those for an $\sim 1$-year component in FH's systolic BP (Halberg et al. 2006a), or in terrorism (Halberg et al. 2008d).

\section{NONPHOTIC CYCLES}

Other projects deal with the already noted basic topics, such as the findings in our circulation of an entire spectrum of new cycles, also found in solar flares, in the solar wind and in other gauges of solar and interplanetary dynamics. The nearly forgotten 30-year BEL cycle, Fig. 5 (Halberg et al. 2008e), and transyears (that have $\tau$ s longer than a year) in the circulation and in 17-ketosteroid excretion, Fig. 6, among others, such as the cis-half-year, are just a few examples. Some of these cycles are discussed in two conference proceedings that are available free of charge online (Halberg et al. 2008e, 2009e).

Transdisciplinary endeavors include the monitoring of cycles putatively associated with societal ills (Halberg et al. 2008d), also detected in data originally collected for personalized health care, far beyond the fashion of molecular clocks that also gains from objective quantification (Sothern et al. 2009). In a $\sim 15$-year series of mostly daily determinations of urine volume and 17-ketosteroid excretion (Halberg et al. 2008c), a component of the spectral structure - the cis-halfyear of $\sim 5$ months 


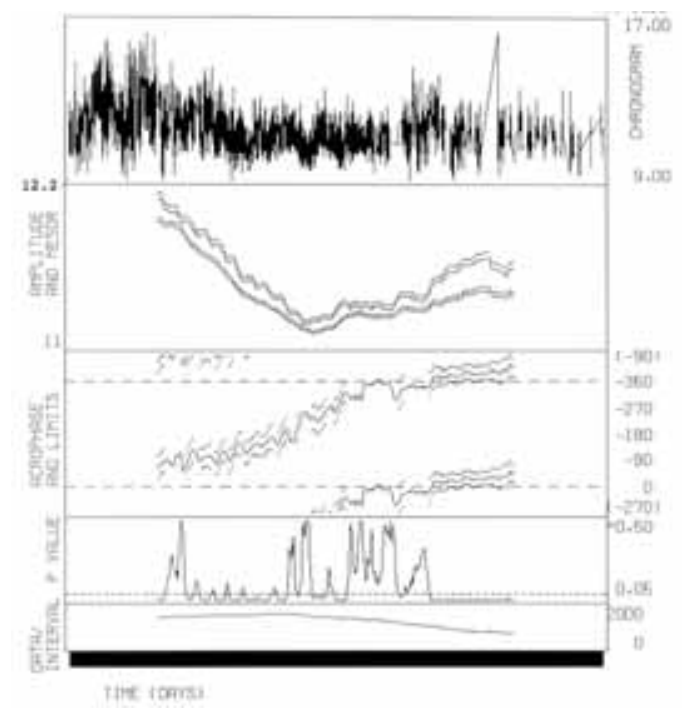

Fig. 2A. Urinary 17-ketosteroid recorded over 15 years in $\mathrm{CH}$, a clinically healthy male scientist 49 years of age at start of study. Chronobiologic serial section shows the daily excretion of 17-ketosteroids (top); in the second row are the MESOR (M, lower curve) and the cis-half-year (0.42-year) amplitude (A, distance between the two curves); dots below the lower and above the upper curves indicate the standard errors of the Ms and As. Acrophases in the third row are shown with dots, corresponding to their CIs (95\% confidence intervals) when results are statistically significant; P-values from the test of the "no 0.42 -year amplitude" are shown in the fourth row $(\mathrm{P}<0.05$ mostly; dashed horizontal line indicates $\mathrm{P}=0.05)$. When the no-0.42-year amplitude assumption is rejected, the time course of the cis-half-year acrophases for 17-ketosteroids appears to mimic that of the acrophases of the cis-half-year of the planetary geomagnetic index, Kp (see Fig. 2B). Overall (globally) in $\tau$, urine volume is congruent with the former two variables, but its phase behavior is transiently congruent only with relative sunspot (Zürich-Brussels) numbers differing in its time course from that of the phase of 17-KS and Kp (Fig. 2C). The two biospheric variables differ in terms of their environmental phase synchronization. Reference time: 21 December 1947, 0.42-year cosine curve fitted to data in 5-year interval displaced by 1-week increments ( $\mathrm{N}$ of data $=3,719$ collected between 23 October 1948 and 23 October 1963).

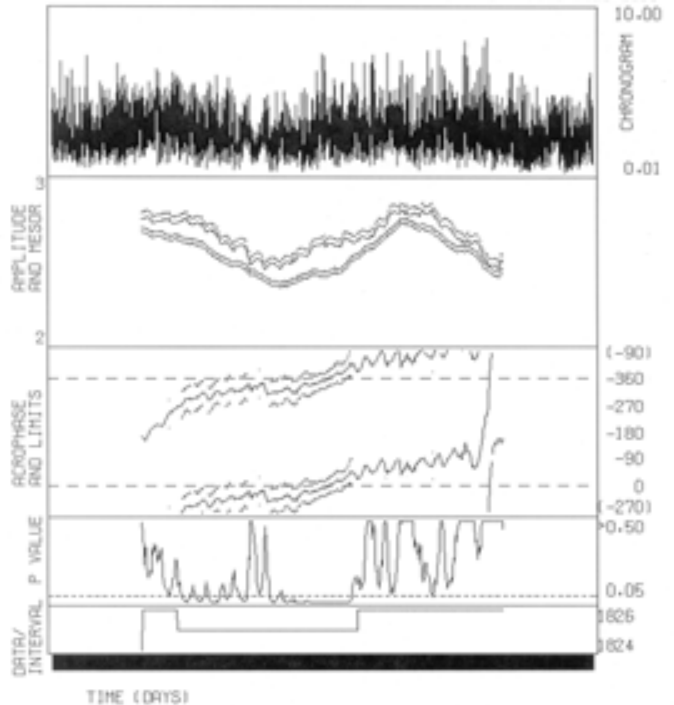

Fig. 2B. Chronomic serial section of the planetary geomagnetic index Kp (23 October 1948 to 29 October 1963), using a 0.42-year trial $\tau$. The time course of acrophases is similar to that of 17-KS in Fig. 2A. Statistical significance is lost toward the end of the record for Kp, but not for 17-KS (see Fig. 2A). Note further at the beginning the lack of statistical significance in Kp, but not in 17-KS, that may be driven by Kp, but this is not suggested by the behavior of the As that are quite large for 17-KS at the end of the record in Fig. 2A, while the cis-half-year is not statistically significant in Kp and its amplitude decreases with time. Time courses of intermittently congruent environmental $\tau$ s concurrent with the persistence of a previously or subsequently 
congruent $\tau$ in the biosphere (when the previously congruent environmental $\tau$ is not detected) serve to resolve partial endogenicity in cosmic-biospheric associations, preferably when time series are equidistant and the longest available. Problems arise when at least one series is unequidistant because of artifacts that can simulate a periodicity when none exists or obscure a real periodicity to the point that it is no longer detected. Reference time: 21 December 1947, 0.42-year cosine curve fitted to data in 5 -year interval displaced by 1 -week increments $(\mathrm{N}$ of data $=5,475$ between 23 October 1948 and 23 October 1963).

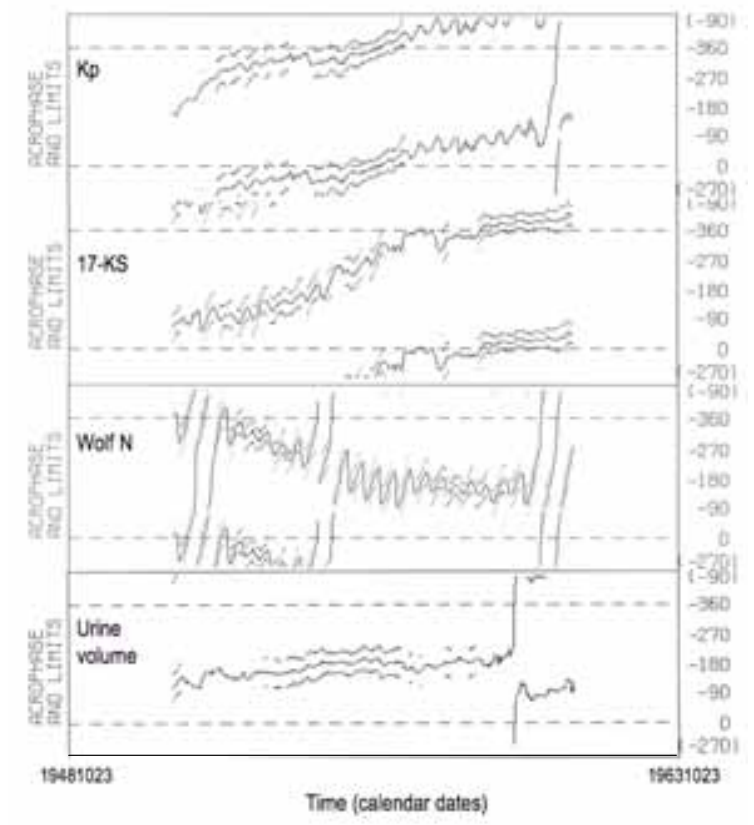

Fig. 2C. Selective congruence of urinary steroid excretion with Earth (Kp) (top half) and of urine volume with Sun (Wolf N) (bottom half) in the same frequency window during 15 years. Congruence in $\tau$ globally (not shown) for four variables does not necessarily imply congruence in phase (but may apply to the top 2 rows that differ, however; bottom). Data from clinically healthy man, $\mathrm{CH}$.

(Wolff 1983, Rieger et al. 1984, Cornélissen et al. 2008 b) - reflects a beat period of rotations at different solar latitudes, with differences in phase among the spectra of variability in 17-ketosteroid vs. urine volume, that share the same $\tau$ of $\sim 5$ months further characterizing melatonin (Cornélissen et al. 2008b); those latter results may allow the study in individuals of mechanisms leading to societal diseases.

\section{PITFALLS FROM IGNORING LIGHTING AND FEEDING SCHEDULES LEAD TO CHRONOBIOLOGY}

It is now customary in science to have an experiment start at zero time, without further specification. The clock hour, however, along with details of lighting and feeding, may be needed as a minimum for a comparison between two groups that may be characterized by circadian rhythms differing in amplitude, phase or frequency. If this is the case, e.g., as differently phased lighting and feeding of two groups being compared, the only way to avoid blunders is to map the rhythmic variation. This is how chronobiology started (Halberg 1969, Halberg et al. 2003). To be specific, Fig. 7A was an incidental finding, a statistically highly significant and seemingly important difference. Fortunately, it was never published alone. Otherwise, had the results of Figs $7 \mathrm{~B}$ and $7 \mathrm{C}$ been found and published by others (they were also not used in themselves by us), controversy could have ensued (Halberg et al. 2003). Problems were avoided by realizing by 1950 that one dealt with a feeding schedule (in the morning, of a diet restricted in calories) that became the dominant synchronizer over the lighting regimen for one of two groups studied, whereas the other group was allowed to feed freely by night during the daily dark (active) span. This circumstance resulted in a phase difference between the circadian rhythms of the two groups, leading to differing results when sampling was 


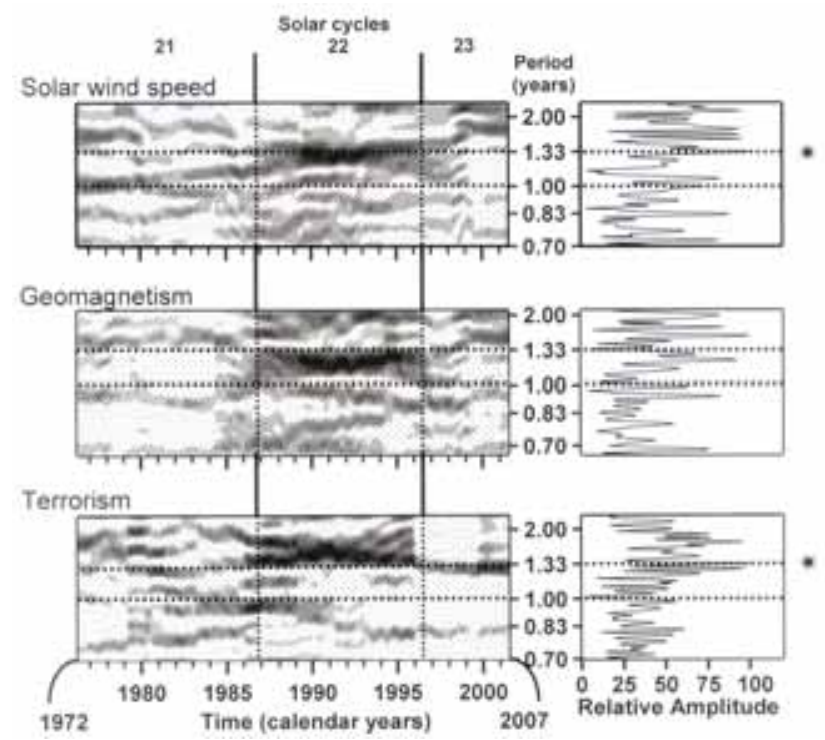

Fig. 3A. Terrorism mimics space weather. Non-photic transyear of about 1.33 -year length is statistically significant (* on right) and dominates in the absence of photic-thermic-social yearly component. Gliding (left) and global (right) spectral windows illustrate the time course and summarize globally, respectively, the seemingly coincidental behavior of two environmental variables (top and middle) and terrorism. Data source: solar wind speed $(\mathrm{N}=11,797)$ from http://www.ngdc.noaa.gov, antipodal geomagnetic index aa $(\mathrm{N}=14,244)$ from http://www.geomag.bas.ac.uk/, $\mathrm{N}$ of terrorist acts $(\mathrm{N}=14,579)$ from http://www.tkb.org/. Gliding spectra computed with 10-year interval displaced by 2-month increment, using a 0.025 harmonic increment in range from 1 cycle in 2.5 years to 0.7 year. Darker shading corresponds to larger amplitude. Nonlinearly, the CIs of the transyear period in solar wind speed and that in terrorism are overlapping (congruent).

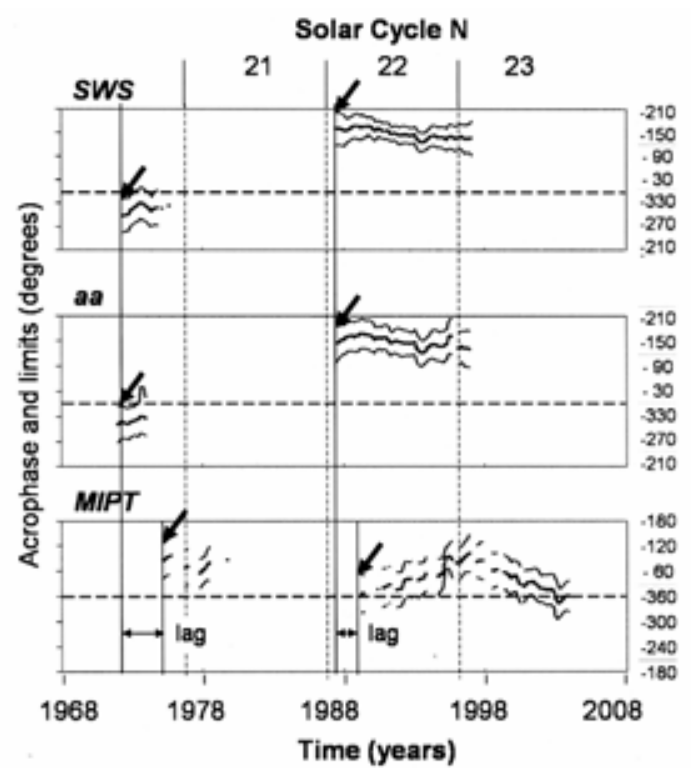

Fig. 3B. Solar wind speed (SWS) (http://omniweb.gsfc.nasa.gov/), geomagnetism (aa) (ftp://ftp.ngdc.noaa.gov/STP/ GEOMAGNETIC DATA/AASTAR) and terrorism (MIPT) (http://www.tkb.org/) show intermittent statistical significance of a congruent 1.36-year (16.27-month) component (seen by bracketing dots, delineating $95 \%$ confidence intervals of the acrophase, a measure of the timing of overall high values recurring in each cycle, obtained by the fit of a 16.27 -month cosine curve by chronobiologic serial section, using an 8 -year interval displaced by 1-month increments throughout the time series). Changes in SWS and aa lead in phase those in terrorism (N/day, assessed monthly) at the seemingly resonant frequency investigated, with terrorism continuing to resonate when the statistical significance of the triggering environmental agents has ceased. 


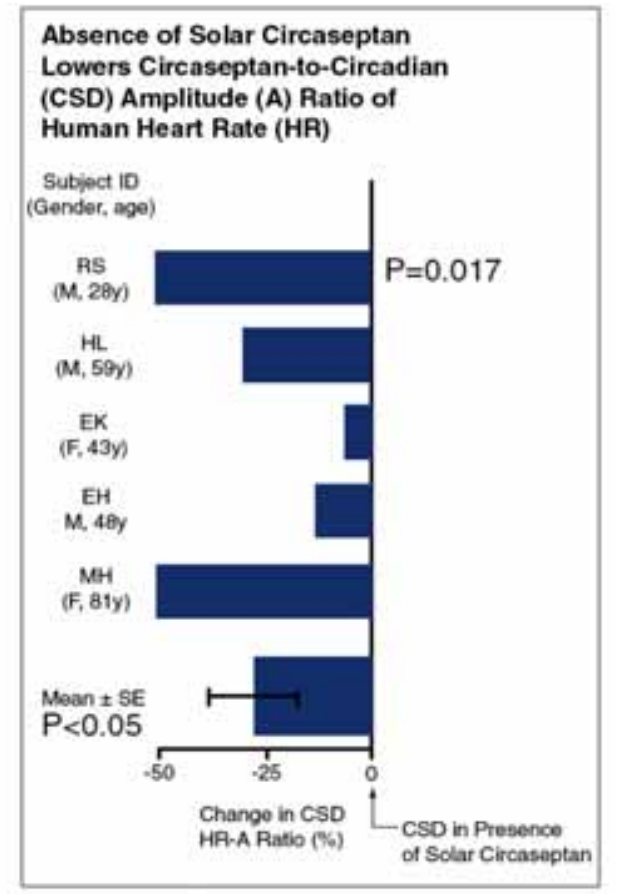

Fig. 4. An 7-day spectral component in the HR of 5 men is less prominent when the solar wind loses its $\sim 7$-day counterpart. Implied is the persistence in the biosphere of an $\sim 7$-day component that can be driven (amplified) by a reciprocal component in solar activity.

restricted to a single clock hour. Fig. 7D shows how this difference was resolved and how problems could readily be avoided.

\section{DESIRABILITY OF RECORDING CALENDAR DATE AND GEOGRAPHIC LOCATION}

As infradian biologic rhythms with $\tau$ s longer than 28 hours are being documented, many nonphotic in origin, counterparts are found, e.g., in cycles of particle radiation from the sun and the galaxies, broadly galacto-helio-interplanetary-ionospherogeomagnetics, gravitation and UV flux, among other variables monitored routinely by physicists with results in the public domain (Silverman 1992, Prabhakaran Nayar 2006, Prestes et al. 2006).

These environmental data can all be aligned with biospheric information only if the calendar date and geographic coordinates, such as longitude(s) and latitude(s) of each experiment or survey are known. Pertinent information gains in importance and pertains even to experiments limited to a few minutes or hours, in order to check at least retrospectively, for instance, as to whether one dealt with a magnetically disturbed or quiet time. Fig. 8 allows the possibility that a magnetic storm may dampen a circadian rhythm in corneal cell division (Halberg et al. 2006c). Fig. 9 shows why one may not generalize in the cartography of an organism, as in the geography of continents (Halberg et al. 2006a). With a magnetic storm, a damping of the MESOR (Midline Estimating Statistic Of Rhythm) and of the circadian double amplitude (a measure of the extent of predictable within-day change) of melatonin in situ in the rat pineal is associated in the same animals with an increase of both MESOR and circadian amplitude of the melatonin rhythm in the hypothalamus (Jozsa et al. 2005) (cf. Burch et al. 1999, Weydahl et al. 2001). Changes in amplitude, even when they occur in the "normal range", can indicate abnormality (Halberg and Cornélissen 1995, Otsuka et al. 1996, Cornélissen et al. 1997, Halberg et al. 2001a). For instance, differences in the opposite directions in the circadian amplitude of melatonin distinguish between health and either breast cancer risk, indicated by an increase in amplitude, or the presence of overt cancer, associated with a decrease in amplitude, respectively (Halberg et al. 2001a). As the circadian amplitude of 1-minute time estimation changes with age, it can 


\section{Brückner-Egeson-Lockyer (BEL) Cycle Historical Macroscopy (top) and Time-Microscopy (bottom)}
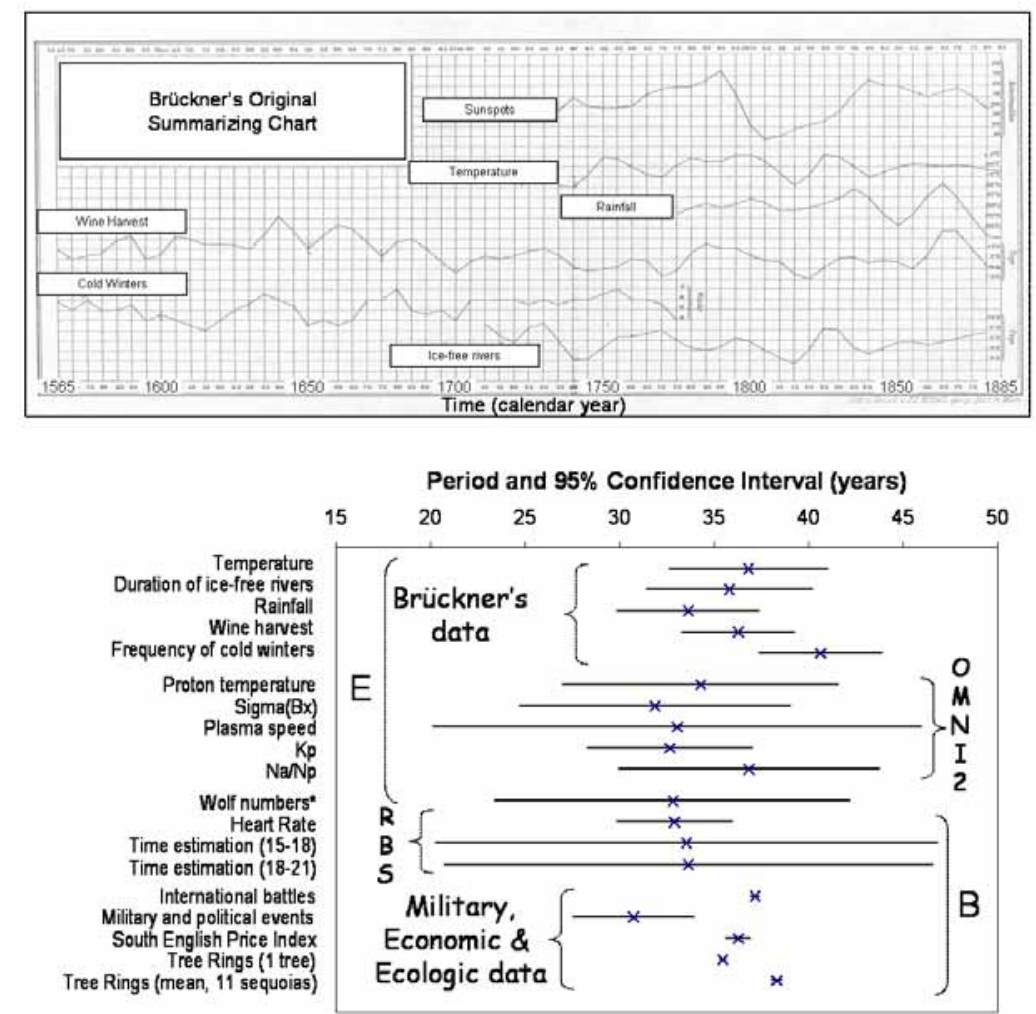

- Same about 40-year span as that of heart rate of 20-60 year-old man (RBS), assessed in 3-component model; RBS also estimated 1 minute by counting; results shown for measurements taken between 15:00 and 18:00 and between 18:00 and 21:00

\section{E: Environment; B: Biosphere}

Fig. 5. Transtridecadal, transdisciplinary cartography. Brückner's and Lockyer's descriptive statistics were repeatedly questioned and, with notable exceptions are forgotten. Brückner's data, taken off his summary chart, are here for the first time inferentially statistically validated as non-stationary (to the point of intermittency) and as transdisciplinary, aligned with periodic changes in the interplanetary magnetic field and extended from meteorology to 2,556 years of international battles, to 2,189 years of tree rings, to $\sim 900$ years of northern lights, to 460 years of economics, to 173 years of military political affairs, to $\sim 40$ years of helio-, interplanetary- and geo-magnetics, and longitudinally to a healthy individual's 4 decades of self-measured heart rate and mental function (1-minute time estimation) and (not shown) to SBP and DBP data of a second person, to the HR of a third, and to earth surface temperature, among other variables. Space weather, mirrored in the circulation of human blood, can be tracked biologically as a dividend from self-assessed preventive health care, involving the automatically and ambulatorily recorded $\mathrm{HR}$ and $\mathrm{BP}$ for detecting and treating heretofore ignored VVDs. A website providing cost-free analyses for those surveying themselves (in exchange for the data) could serve any community with a computer-savvy member and could start focus of the population at large on problems of societies' as well as individuals' health. (Solar cycle length, reported as periodic by the Lockyers, and climate were subsequently revisited without reference to any cyclicity or its discoverers.)

possibly underlie trends in the opposite directions when measurements are taken at different clock-hours, Fig. 10.

As chronobiology, the study of biologic rhythms, will be complemented by the investigation of associations with the cosmos, by chronomics, precautions in indicating not only photic but also invisible yet measurable nonphotic conditions may become indispensable in reports of scientific results. Such investigations will be facilitated by indications of universal time, the form in which physical data are usually provided, and of geographic site(s).

Data coding for chronobiological analyses uses as format cnyrmodahrmn, where $\mathrm{cn}, \mathrm{yr}, \mathrm{mo}, \mathrm{da}, \mathrm{hr}$, and $\mathrm{mn}$ stand for century, year, month, day, hour and 


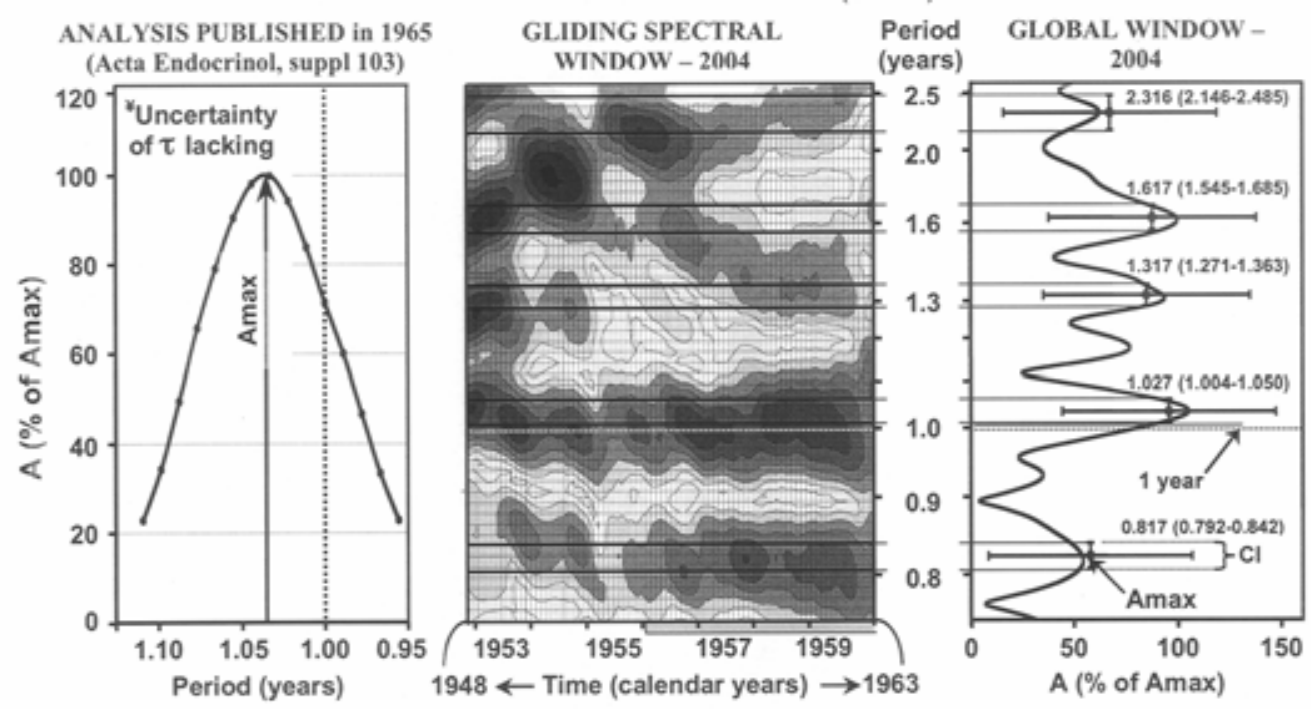

Fig. 6. In 1965 (left): apparently desynchronized biologic year. In 2004 (middle and right): several transyears (1-year asynchronized components) characterize a 15 -year record $(\mathrm{N}=3,719)$ of human urinary 17-ketosteroid (17-KS) excretion of a clinically healthy man (CH, 43-58 years). Gliding spectrum computed with 8-year interval displaced by 1-month increments, using a 0.05 harmonic increment in the range of one cycle in 2.265 years to one cycle in 0.75 year. Darker shading corresponds to larger amplitude (A). Shading on abscissa in middle graph indicates span of intermittent androgen treatment (data during treatment omitted from analysis).

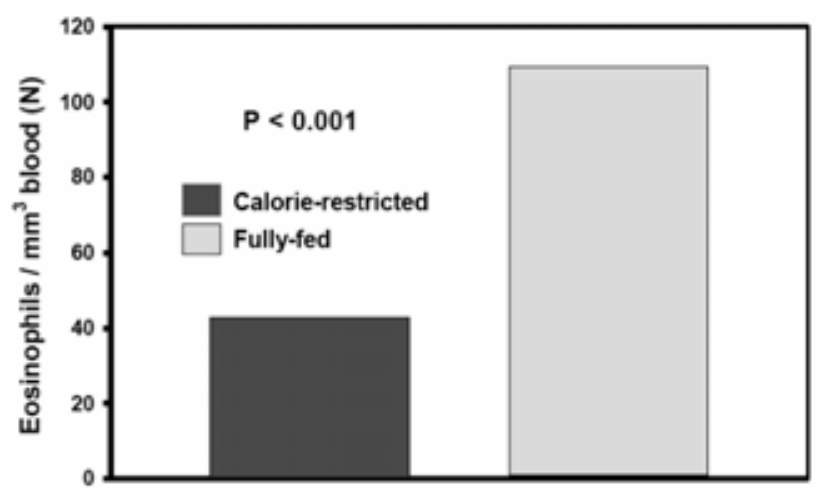

Fig. 7A. Eosinophil counts lowered by "fasting" and/or "stress". Effect of a 50\% reduction in dietary carbohydrates and fats (with proteins, vitamins and minerals as in control group) in $\mathrm{C}_{3} \mathrm{H}$ mice with a high breast cancer incidence (not shown), which is greatly lowered by a diet reduced in calories. Is an adrenocortical activation, then assessed by eosinophil depression, an answer for treating breast cancer and for prolonging life? An exciting finding - a difference in eosinophil count between two groups of mice - was found, and of course it had to be replicated on a larger group of animals because of its importance to the etiology of cancer. Steroids that depress eosinophil cell counts and perhaps mitoses could be a mechanism through which caloric restriction and ovariectomy act in greatly reducing cancer incidence. This may be the mechanism to prevent breast cancer, or was this very reasonable and plausible hypothesis a premature extrapolation? (My chief had taken these results as a statistically significantly validated, most promising report to Paris.) 


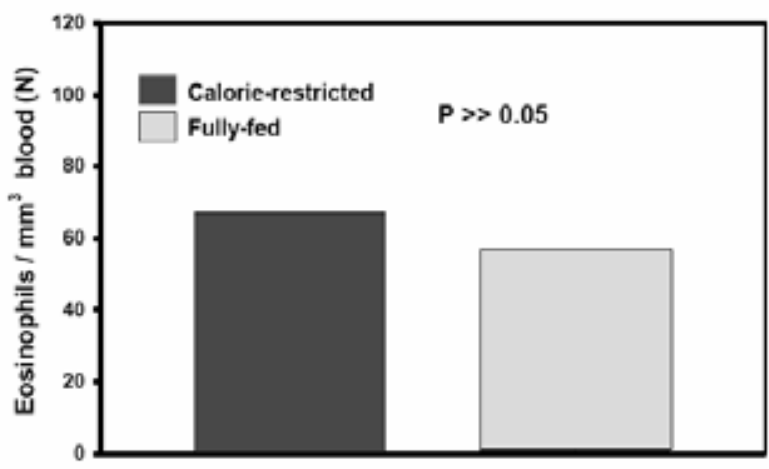

Fig. 7B. Confusing results one week later: follow-up with more animals starting at an earlier clock hour shows "no difference" (prediction of a phase difference between groups?). A phase difference between the two groups was predicted. The large inter-group difference in eosinophil count was not replicated when more animals were used with an earlier start.

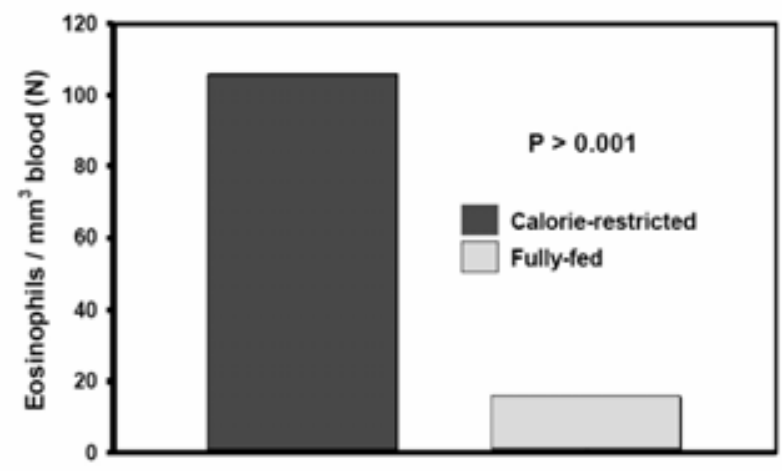

Fig. 7C. Opposite outcome observed another week later: has "stress" become "allergy"? Erroneous conclusions from ignoring a phase difference in circadian rhythm due to competing synchronization. Results from another follow-up with even more animals at a yet earlier clock hour. A difference in the opposite direction as compared to the difference observed first (Fig. 7A) is noted.

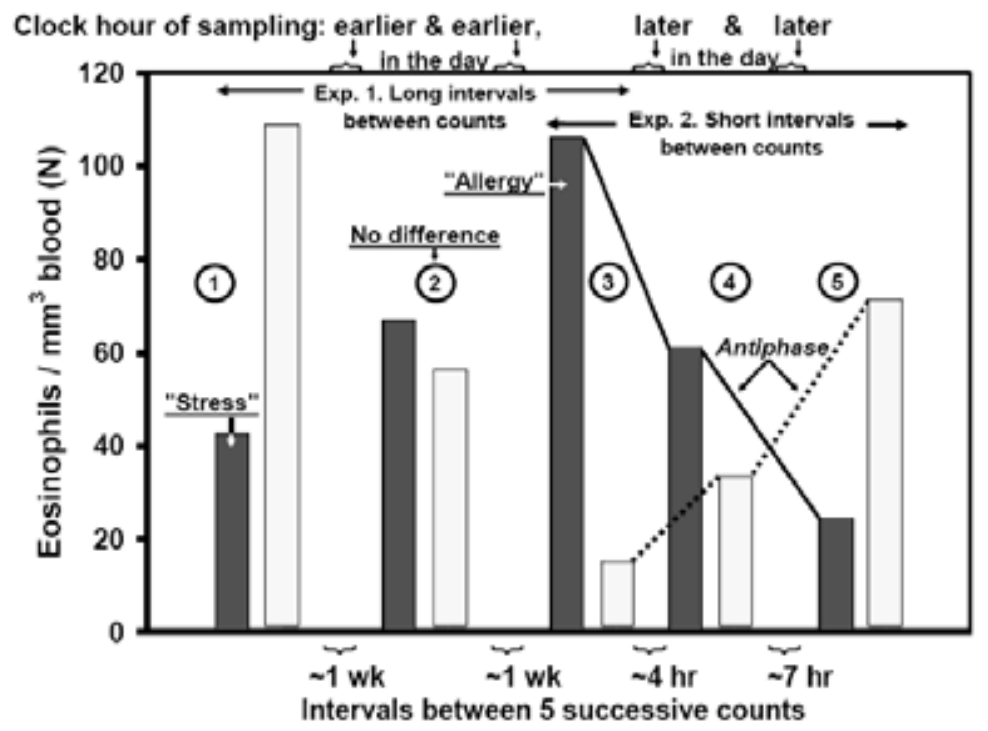

Fig. 7D. Recognition of circadian phase difference between two groups of mice prevents the drawing of false conclusions. Light gray: fully-fed group; dark gray: calorie-restricted group. Two groups of $\mathrm{C}_{3} \mathrm{H}$ mice (with differing breast cancer incidence) 
compared at single but different clock hours, first at near-weekly intervals (1,2 and 3) and then at about 4- and again about 7-hour intervals ( 4 and 5) on the same day. The first 3 samplings at weekly intervals were made at earlier and earlier clock hours on two groups whose circadians were in antiphase, since one was fed a calorie-restricted diet in the morning, while the other group was fed ad libitum and fed mostly during the nightly dark span. To validate this assumption, the final two samplings at about 4- and then at about 7-hour intervals on the same day showed, as anticipated, the predicted reversal of the inter-group difference. (A progressive lowering of count associated with repeated blood letting had been demonstrated separately.) The time of day of sampling was the same for the two groups compared, but it differed from comparison to comparison in Figs 7A-C (circled 1,2 and 3); this fact confounded the results, as documented by repeating sampling at different clock-hours on the same day (circled 4 and 5). This circumstance accounts for the different results in Figs 7A-C: 24-hour synchronized rhythms were compared on the same lighting but on different feeding regimens, as we realized and then documented the dominant synchronizing role of feeding time (overcoming the effect of lighting on a diet restricted in carbohydrates and fat by $50 \%$ ).

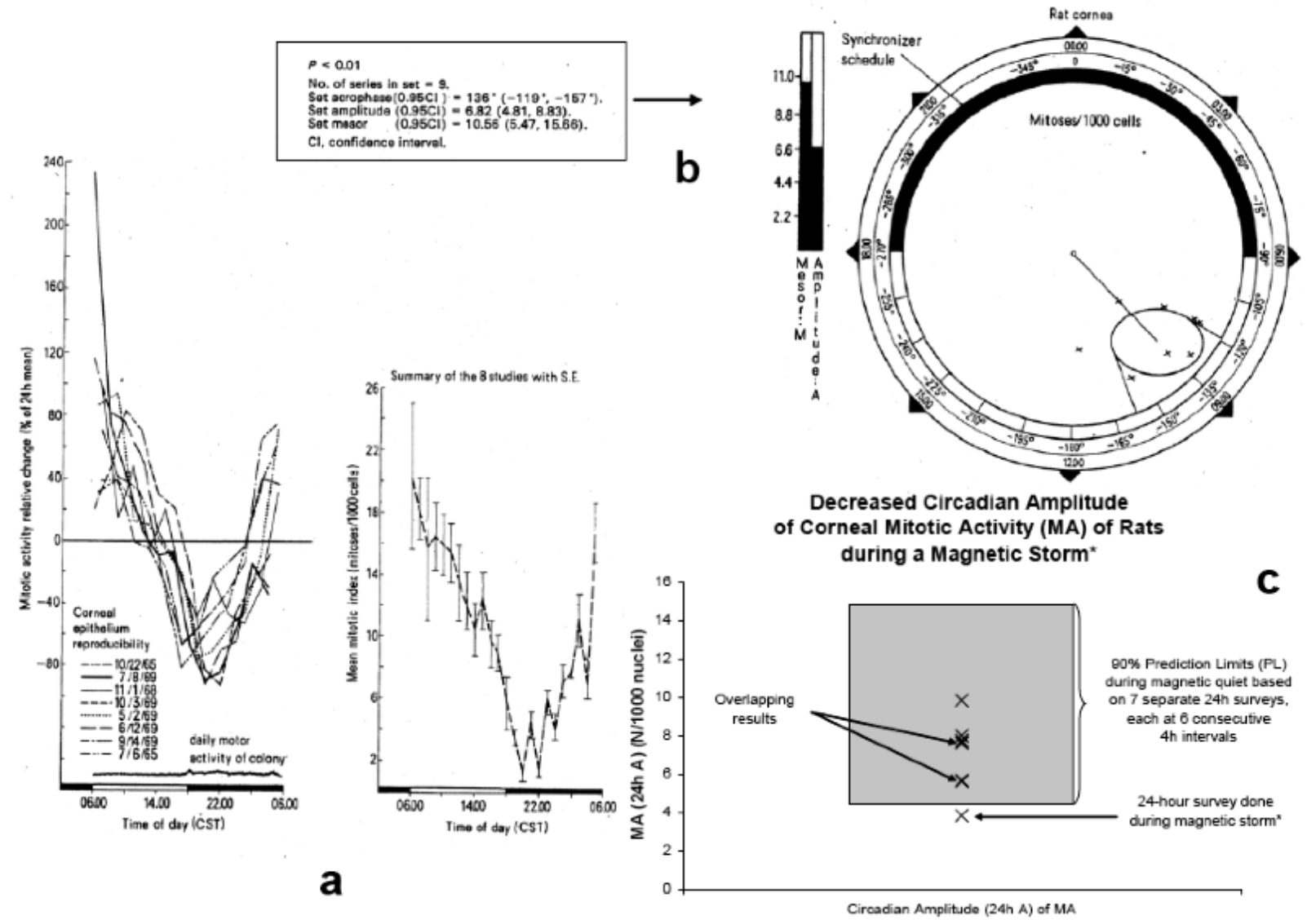

Fig. 8. Eight around-the-clock surveys of corneal cell division (first graph on left, a) are summarized as averages with the uncertainties involved in the second graph from the left in the time domain and in the cosinor display on the top right in the phase domain. One of the surveys had a damped circadian amplitude which fell outside the lower $5 \%$ limit of a $90 \%$ prediction interval, computed on the basis of the other 7 surveys, as seen on the right in the lower graph. That particular study happened to be done on a day with a magnetic storm. All original data (left) from the late Lawrence E. Scheving. 


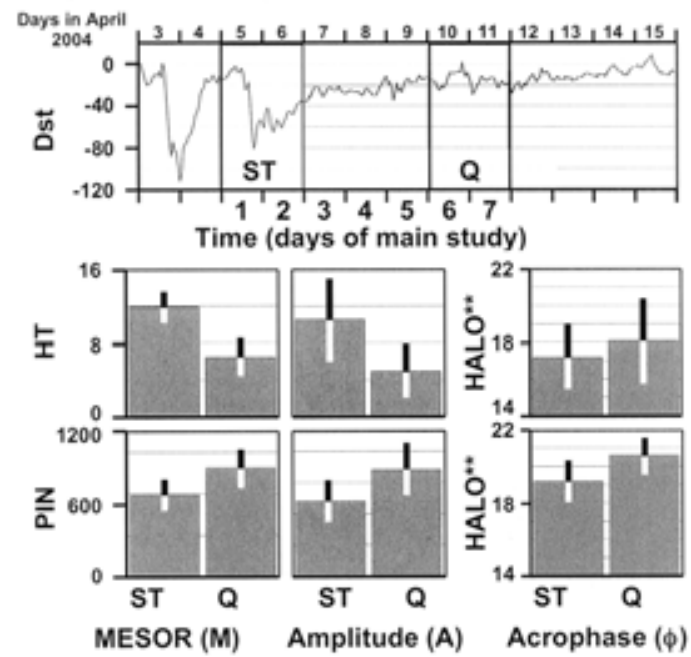

Fig. 9. Melatonin dynamics in rats' hypothalamus (HT, middle) and pineal (PIN, below) during 2 days of the second part of a moderate double magnetic storm (ST) and 2 days of magnetic quiet (Q), gauged by the geomagnetic equatorial disturbance index Dst (in nT) (top). HT may be activated via the storm directly and/or via PIN. Concerning an effect of the storm upon the neuroendocrine network, also involving the adrenal cortex (not shown), these unplanned observations on rats can be aligned with observations of a decreased urinary excretion of melatonin during magnetic storms in keeping with a damping of pineal function, including its dynamics, gauged by the lower circadian amplitude during the storm, concurrent with an increased such amplitude and MESOR in the hypothalamus of the same animals. This "experiment of nature" offers a putative mechanism that cannot be dissected in vivo in humans. Nonetheless, post hoc ergo propter hoc reasoning and confounding by any unassessed effects upon circaseptan rhythms cannot be excluded and will require rebuttal or confirmation. A solution may be most readily available if investigators of pineal function check the presence or absence of a magnetic storm during their studies and, if so, compare data from magnetically stormy and quiet days after the cosinor-computation of parameters. In any event, original data or circadian parameters with calendar dates can be sent to corne001@umn.edu for integration with the results summarized herein and elsewhere. HALO: hours after light onset. Bars are means and 95\% CIs. $\mathrm{P}<0.05$ for each comparison, except for $\Phi$ in HT.
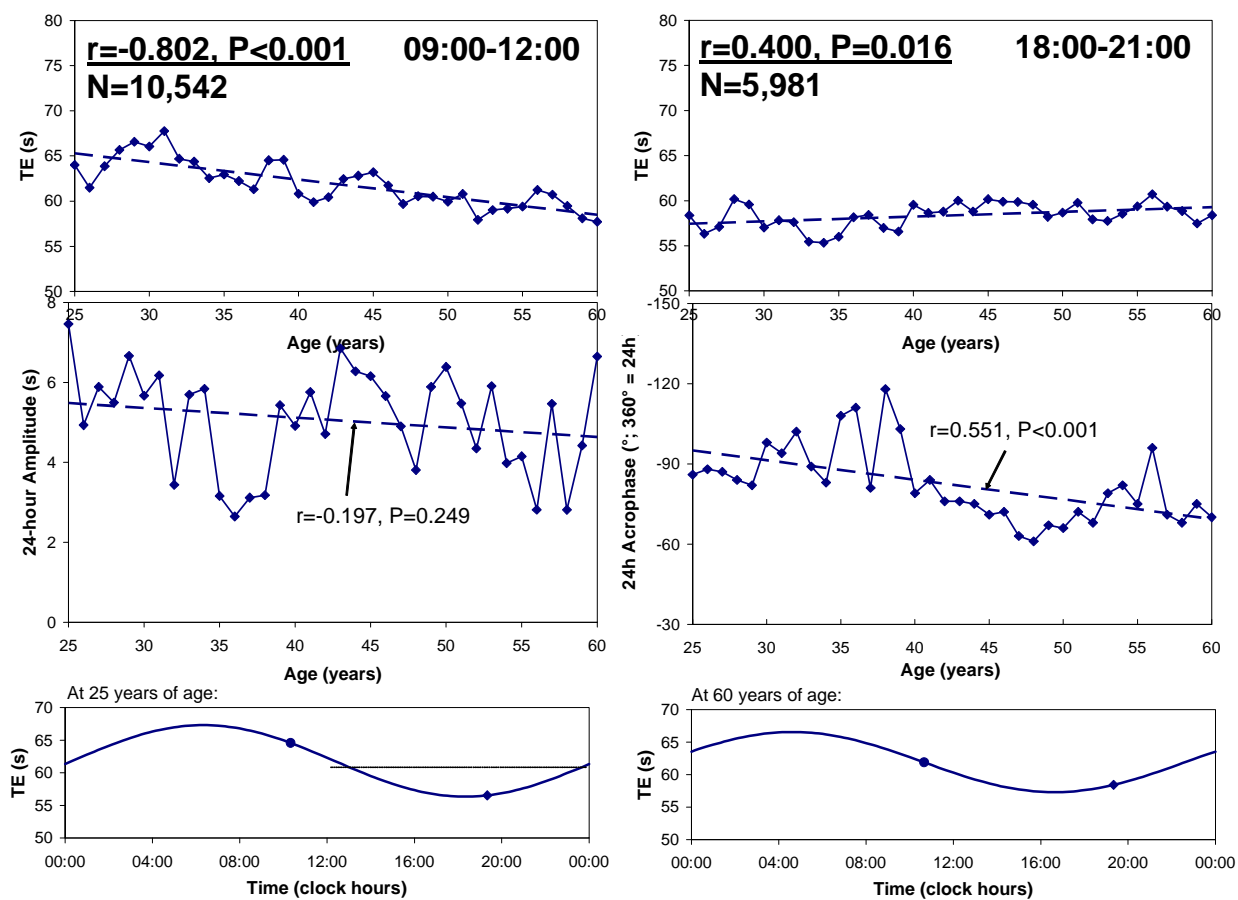

Fig. 10. With advancing age, 1-minute time estimation (TE) takes less time in the morning (top, left) but more time in the evening (top, right). Opposite trends with age are accounted for in part by a small decrease in circadian amplitude (middle, left) 
and an advance in circadian acrophase (middle, right). In the absence of a change in mean, reconstructed circadian patterns at 25 and 60 years of age illustrate how single time-specified measurements can yield opposite results. Data from RBS, clinically healthy man, 25 years of age at start of 1-minute estimations $\sim 5$ times a day for 36 years, resulting from changes with age in circadian parameters.
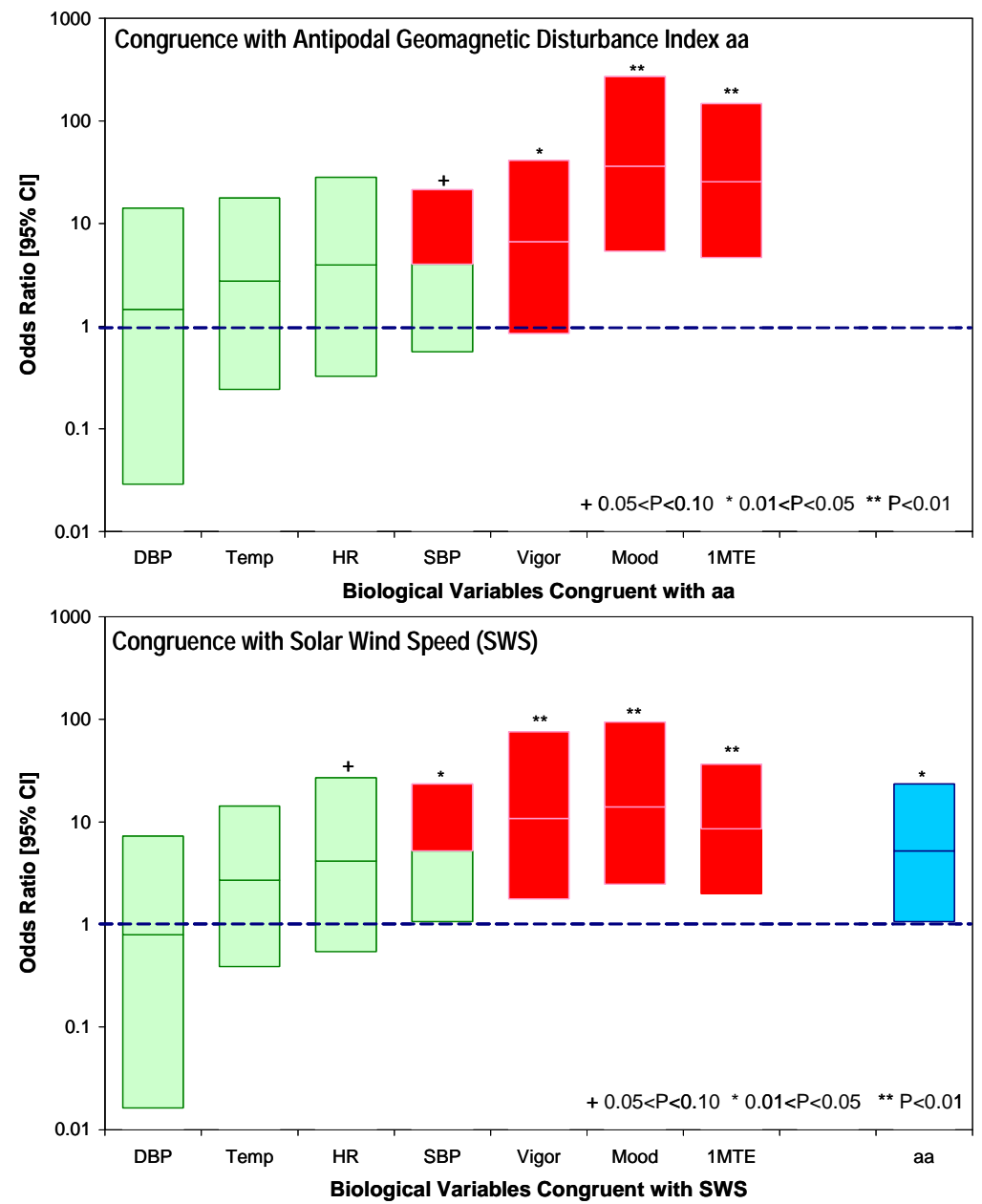

Fig. 11. Biospheric congruence with magnetism of Earth (top) and Sun (bottom). Some inferentially statistically validated congruences of human somatic and mental functions with the environment, gauged by the antipodal geomagnetic disturbance value (aa) (top) and solar wind speed (SWS) (bottom) (c.f. Sothern et al. 2004, 2008). While limited to a single clinically healthy case, RBS, a man aging during the study from 20 to 60 years of age, discussed in detail elsewhere (Halberg et al. 2008g), the number of congruences found for the estimation of 1-minute and for mood in the spectral range investigated (from one cycle in 2.5 years to 3 cycles per year) more than equals that of the known association of helio- and geomagnetism, commented upon by Gen. Sir Edward Sabine (on the basis of too few data) - “... it is certainly a most striking coincidence, that the period, and the epochs of minima and maxima, which M. Schwabe has assigned to the variation of the solar spots, are absolutely identical with those which have here been assigned to the magnetic variations" (Sabine 1852) - and extended to the solar wind by Marcia Neugebauer (1997) and qualified by Gordon Rostoker and Carl-Gunne Fälthammar (1967) and by Wolfgang Baumjohann and Gerhard Haerendel (1985). When congruence is assessed by means of the odds ratio based on the non-central hypergeometric distribution, mental functions show higher congruence than somatic functions; among the latter, systolic BP is responsive, perhaps constituting a seemingly acceptable approximation for the mental functions. P-values are based on the non-central Fisher hypergeometric distribution, with 95\% CIs computed using Fisher's exact test, used since the null hypothesis was rejected in some, yet not all cases. DBP: diastolic blood pressure, Temp: oral temperature, HR: heart rate, SBP: systolic blood pressure, 1MTE: 1-minute time estimation. SBP approximates higher congruence with environment of mental (red) (versus somatic, green) functions that compare favorably with congruence of aa versus SWS (blue, bottom right). 
Halberg et al.: Personalized chronobiologic cybercare
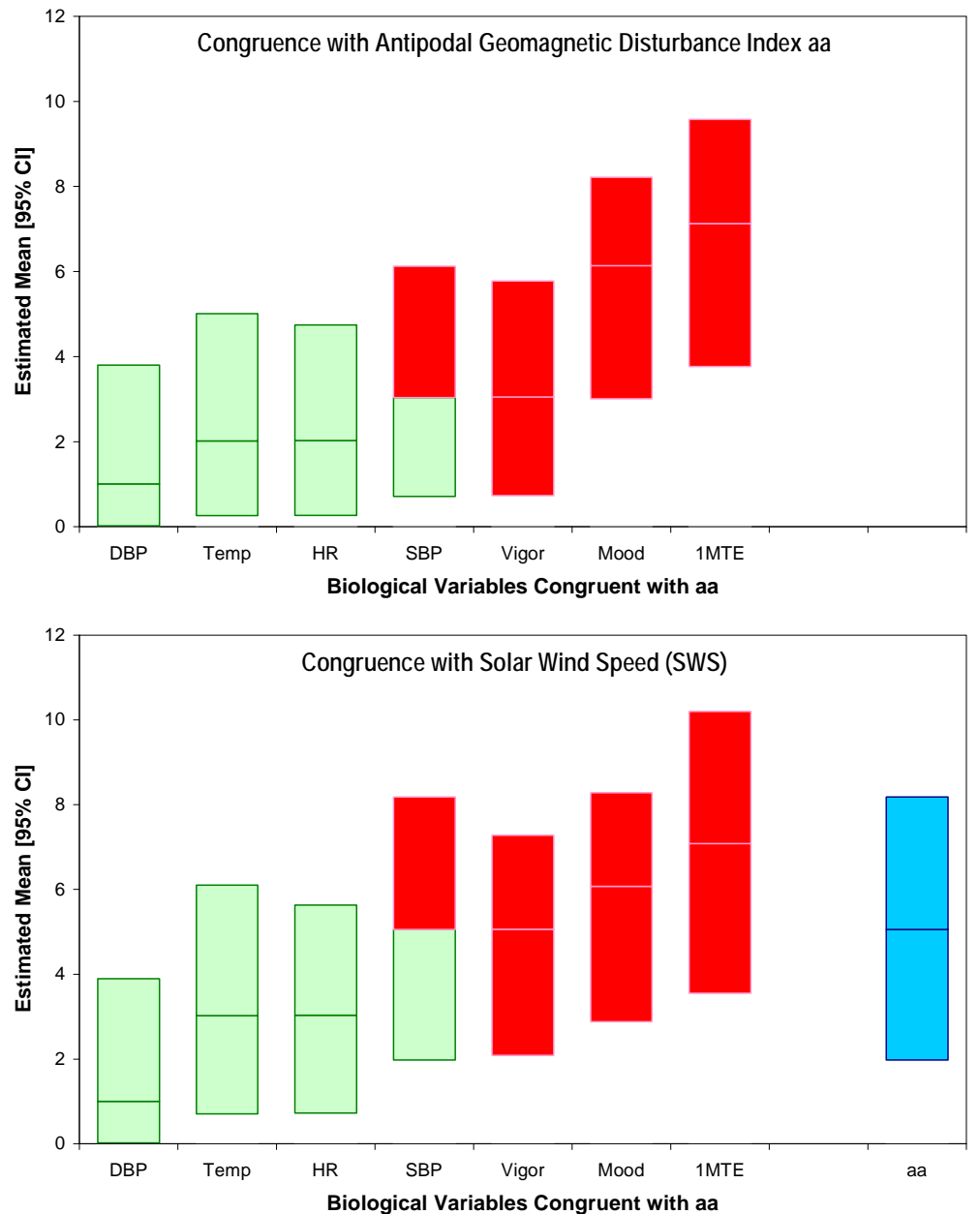

Fig. 12. Mean number of congruences and corresponding $\mathbf{9 5 \%}$ CIs for several mental and somatic functions of a clinically healthy man (RBS) with magnetism from Earth (aa, top) and Sun (solar wind speed, bottom). Results derived from the odds ratios in Fig. 11.

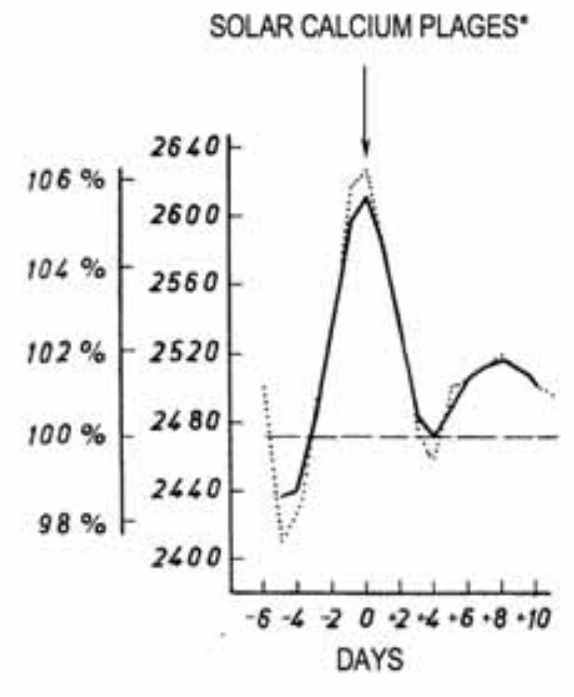

$$
\begin{aligned}
& 0 \text { corresponds to calendar dates } \\
& \text { with most calcium plages in the } \\
& \text { center of the sun }
\end{aligned}
$$

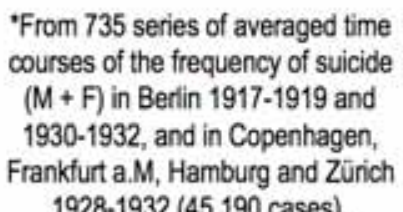

Fig. 13. Calcium plages and human suicides peak at the same times, as reported by Düll and Düll (1938). 


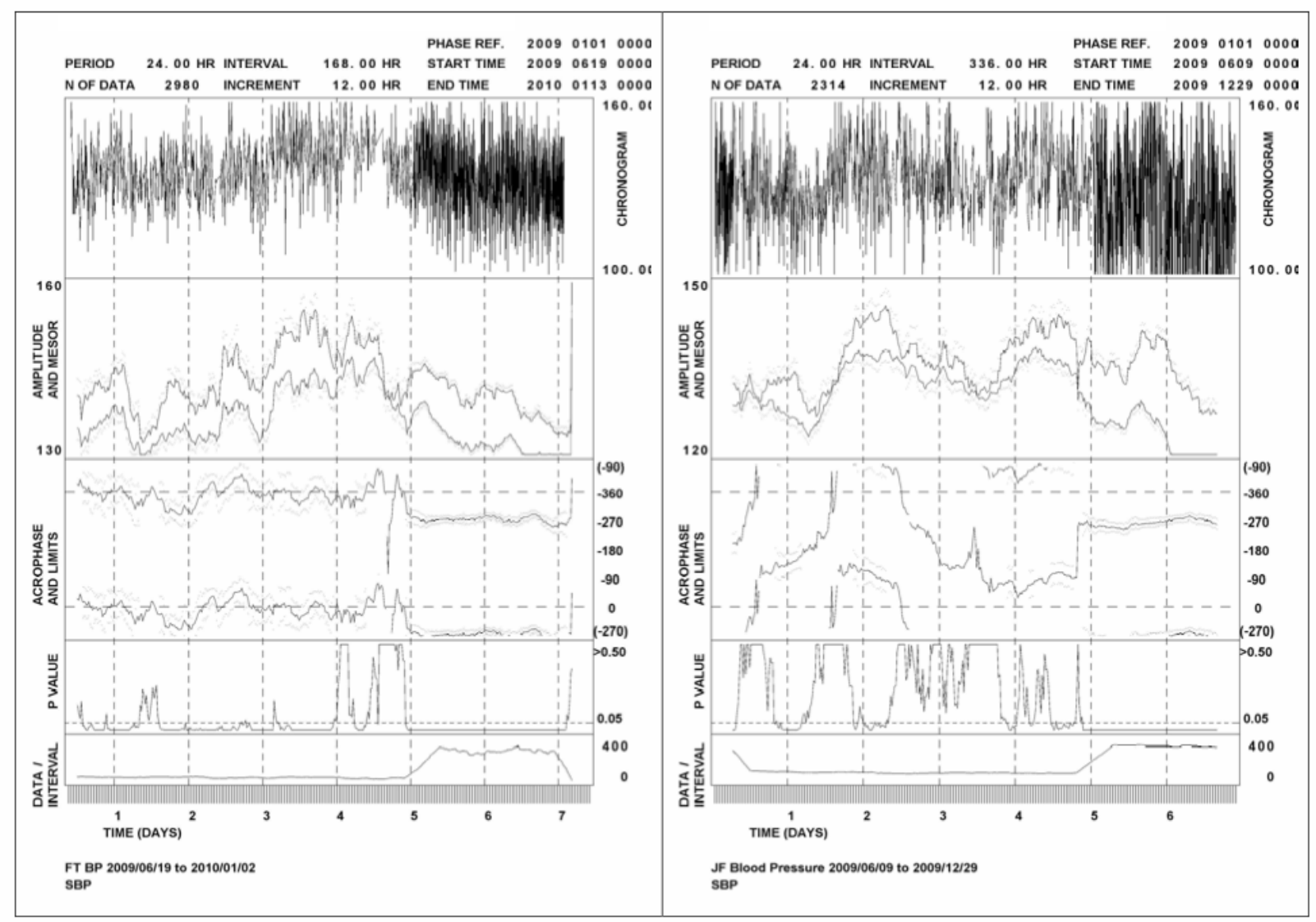

Fig. 14. Automatic dense monitoring assesses circadian timing when disciplined self-measurement fails to do so. Two chronobiologic serial sections analyzing, as the name implies, consecutive sections of a time series by the fit of a component preferably isolated from the series as a whole (not shown). The section length is dubbed "interval" and the length by which it is displaced is the increment usually shorter than the interval, as specified on top of the graphs for FT (left) and JF (right). The top row of each graph displays the self-measurements to start with, up to the fifth vertical dashed line and thereafter the automatic measurements that followed, after the subjects received the instrumentation for ambulatory blood pressure monitoring (ABPM). The data display on top offers limited information for the naked eye; it visualizes the change in data density with the transition to automatic recording. The vertical dashed lines indicate the time of the full moon since the subjects stated to be sensitive to the moon's phases. JF and FT, exceptionally motivated subjects, are a 61-year-old grandmother (JF) and her 42-year-old daughter (FT), with $\sim 4.5$ months of around-the-clock self-measurements made every few hours during wakefulness, followed by two more months of half-hourly automatic measurements. The self-measurements included one of the twice-yearly (winter and) summer "down time" (gauged by self-ratings during wakefulness) by JF and FT. In the second row with two curves, the lower is the MESOR, M (short for midline-estimating statistic of rhythm) of each display. The distance from the $\mathrm{M}$ to a dot below the M shows the standard error of the M. The difference between the lower and upper curves corresponds to the extent of change, dubbed the amplitude, A. Infradian changes are readily apparent by inspection in $\mathrm{M}$ and $\mathrm{A}$ and await the accumulation of more data. Analyses reveal gross abnormalities, namely failures to detect a circadian rhythm in systolic (S) blood pressure (BP) of JF (row 4). The 24-hour rhythm was mostly not statistically significant for JF, but was mostly significant for FT. A reduction of the uncertainty in the acrophase by tighter dots above and below it, indicating the width of the $95 \%$ confidence interval in FT, and a phase jump are seen for both JF and FT at the transition from the self-measurements to the automatic measurements, with both patients having a similar phase position in the analysis of the automatically collected data. (More generally, in practice, automatic instrumentation is desirable for a reliable determination of the phase of circadian rhythmicity, for diagnosis and as a guide for accordingly timed treatment.) 


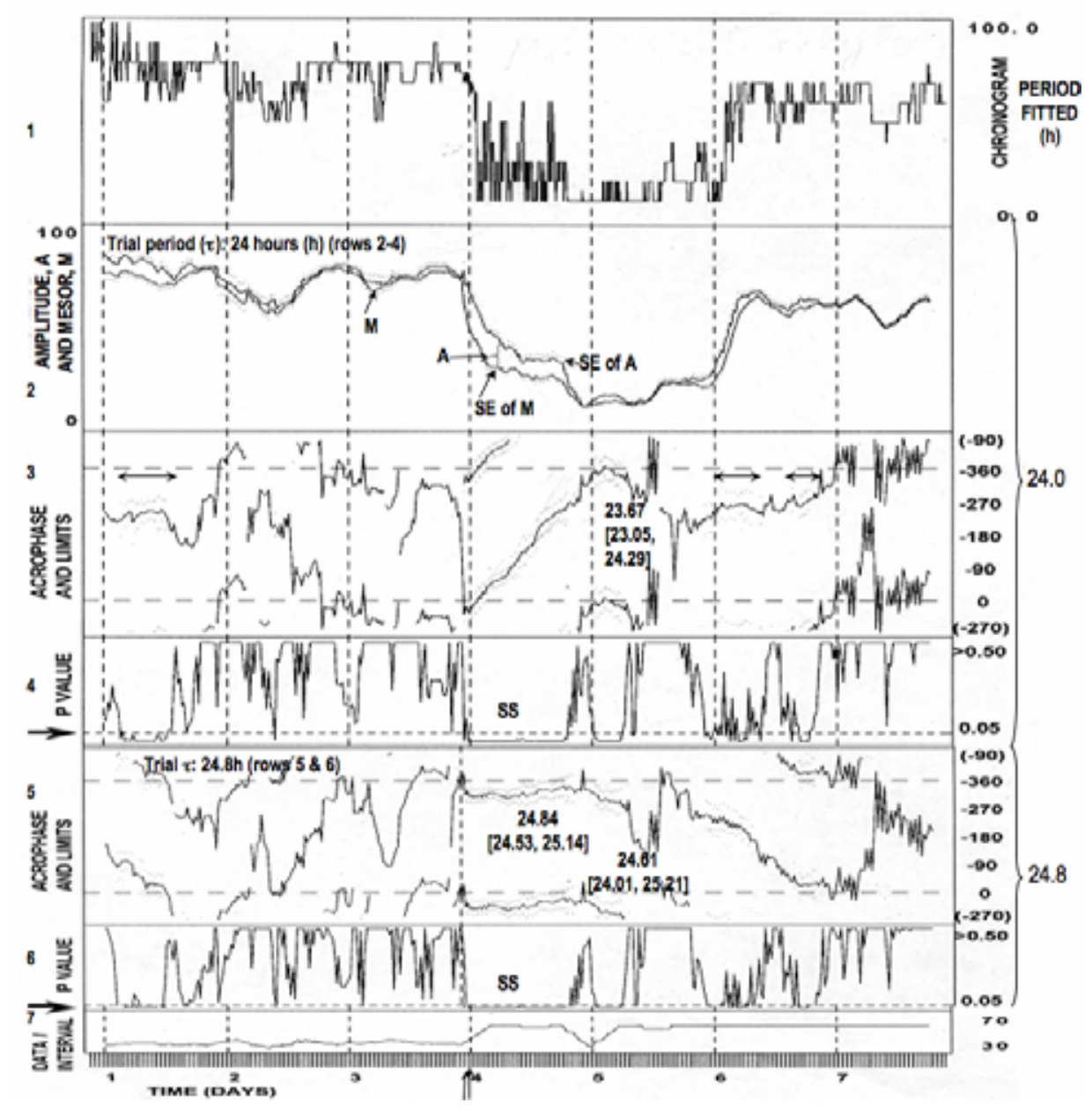

Fig. 15A. Mostly absent circadian periodicity emerges transiently with putative lunar synchronization at the start of a downturn in self-ratings of vigor/well-/unwell-being ( $\mathrm{N}=1,364$ from 7 March to 30 September 2009) by a 61-year old woman (JF), a patient with extreme depression and unwell-being in January/February (not shown) and again in the summer. During the down-time, a period corresponding (to the second decimal) to the double period of tides (Doodson 1921) is noted. This finding, in inferential statistical terms, from an objective analysis made on data from an intelligent individual who herself claimed, before the monitoring started, that she was dependent upon lunar phases, cannot be faked. This putative lunar effect follows up on the observation by Miroslav Mikulecký, emeritus professor and department head of internal medicine and professor of statistics at Comenius University, Bratislava, who reported a lunar effect in his own cardiac physiology. It is tempting to speculate whether a precise double tidal (lunar?) synchronization for a full lunar cycle in JF, occurring after asynchronization of her vigor ratings for 3 prior lunar cycles is a chance coincidence; the correspondence to the second decimal with an average double tidal period is noteworthy nonetheless. The circumstance that this lunar synchronization coincided with the start of the deep depression in a person having noticed some dependence upon the moon can be considered as supporting the assumption that the lunar synchronisation is undesirable. Whether or not it will be repeated, one may also ask whether the lunar synchronization might be good, as the body's defense, rather than bad or indifferent. Circadian dysfunction can alter lifespan in fruit flies (Kumar et al. 2005); and in face flies, shifts of the lighting regimen repeated every 4 days are associated with a longer survival time than that of unshifted controls (Hayes et al. 1986). A period of 24.84 hours was also found in temporal isolation on days 6 to 10 of the core temperature of 12 young men (Endo et al. 1999) as a transient in progressive lengthening. The lengthening found as a function of the duration of isolation has a counterpart as a function of light intensity in female Minnesota Sprague-Dawley rats kept in continuous light of 5 lux intensity (Halberg et al. 1971). On the basis of other data, Frank A. Brown Jr. had suggested that circadian rhythms in mammals are subject to period lengthening from lunar influences (Brown 1965a, 1965b). Studies with a lunar laboratory are indicated (Halberg et al. 1971). There may be an interaction of light intensity and lunar effects, clarified perhaps if the putative lunar effect is removed (Halberg et al. 1992). SS: statistically significant $(\mathrm{P}<0.05)$. Results from chronobiologic serial sections of 24-hour (rows 2-4) or 24.8-hour (rows 5 and 6) cosine fit in intervals spanning 7 cycles displaced by 12 -hour increment. Vertical dashed lines correspond to full moons. Vertical arrows (abscissa) indicate backtracked start of unwell-being and its detection by CUSUM. 


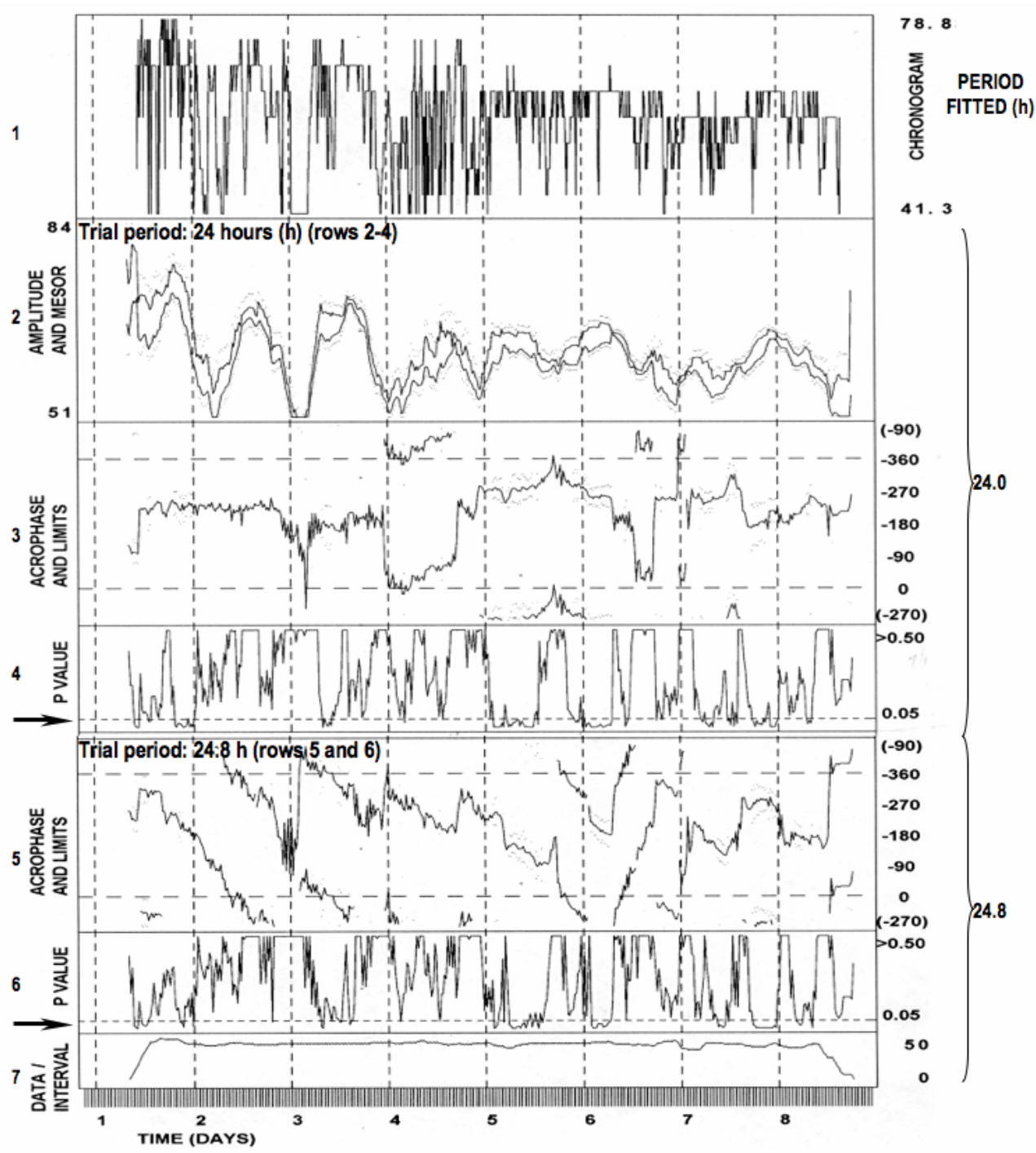

Fig. 15B. Failure to demonstrate a consistent periodicity of about 24 hours in self-ratings of vigor-well/unwell being by a 41-year old woman, FT ( $\mathrm{N}=1,255$ from 23 March to 23 October 2009). Note mostly absence of statistical significance indicated by a dashed horizontal line in rows 4 and 6 (arrows); complete absence of any $\mathrm{P}<0.05$ characterizes, e.g., the second lunar cycle with the 24 -hour fit. Very few P-values reach 0.05 and many are $>0.50$. Results from chronobiologic serial sections of 24-hour (rows 2-4) or 24.8-hour (rows 5 and 6) cosine fit in intervals spanning 6 cycles displaced by 12-hour increment. Vertical dashed lines correspond to full moons. Note change in 24.0-hour acrophase (row 3 ) occurring around full moon \#4.

minute (Hillman and Halberg 1988). This format proved to be very useful in numerous applications as it was adopted worldwide for research in chronobiology. As chronobiology led to chronomics, several new issues needed to be addressed, requiring refinements to the data coding protocol.

One issue relates to the availability of ambulatory monitors that automatically record physiologic data at intervals. Whereas data series comprised primarily short records in the past, longitudinal profiles spanning months, years, and even decades have accumulated. As long as only short records spanning days or weeks were obtained, coding the data collected in Minnesota in central standard time (CST), as originally proposed (Halberg et al. 1972), posed no problem. Analyses of data collected over spans of a year or longer, however, revealed a clear 1-hour shift in acrophase after a change from CST to daylight saving time (DST) and vice versa. As such changes in acrophase can cause spurious spectral peaks (Halberg et al. 2008f, Cornélissen et al. in press), the preferred recommendation is to code data 


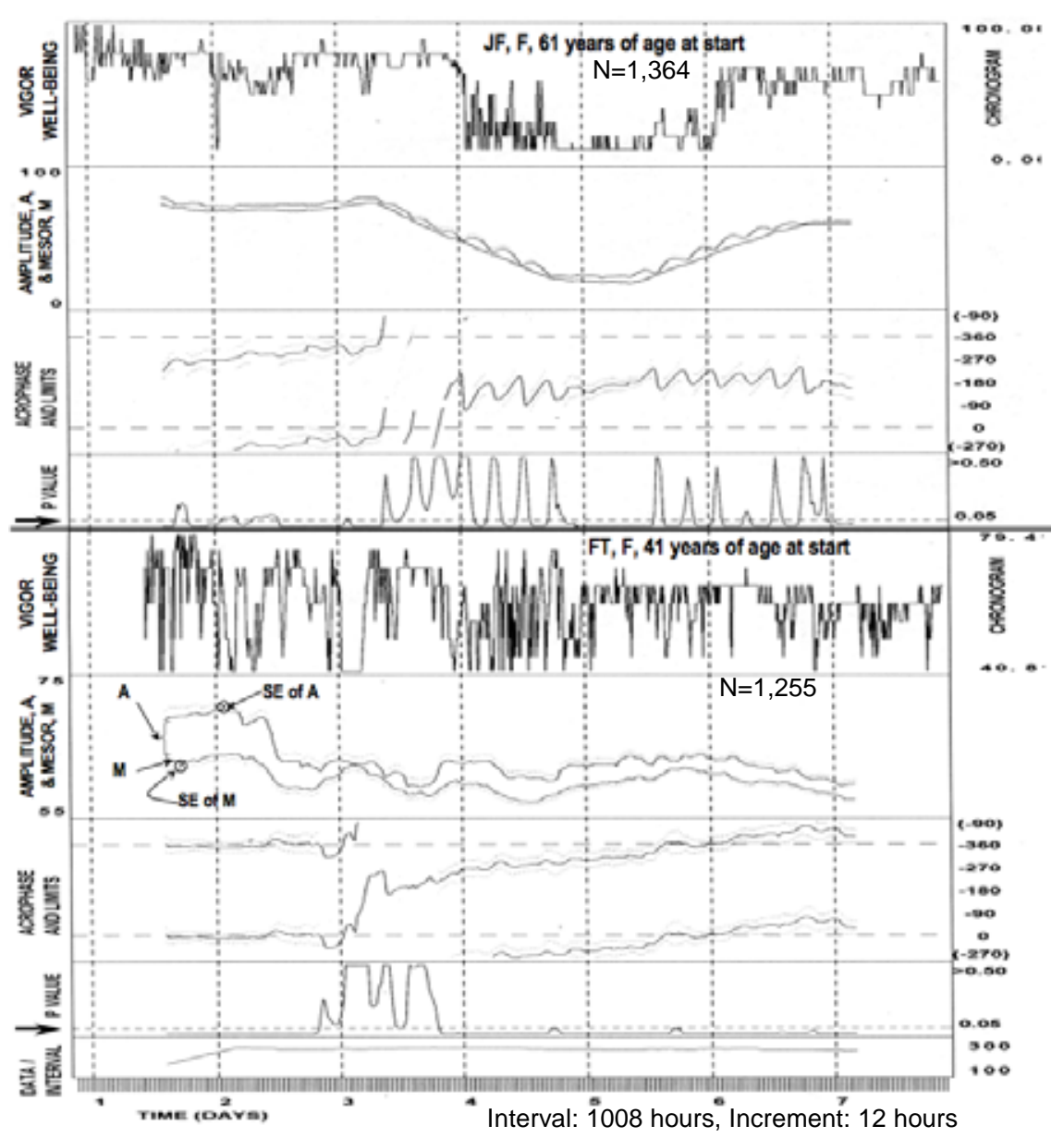

Fig. 15C. Mostly statistically significant about-7-day (circaseptidian, briefly circaseptan) rhythm in two members of a putatively magnetolabile family's self-ratings of vigor and well/unwell being (JF: top, FT: bottom; 7 March to 1 October 2009). In JF, with a trial period of 1 week, a phase-jump occurs at full moon (FM) \#4, corresponding to the fourth dashed vertical line. Not shown are least squares spectral results of different portions of JFs record that indicate a period of $\sim 174.5$ hours at the start, shortening to $\sim 172.7$ hours during the major depressed episode (see top row) and further to $\sim 168.7$ hours thereafter, when ratings improved. It seems pertinent to note that healthy students testing their positive and negative affect (with the PANAS scale) had a circadian prominence in the positive affect and a circaseptan in the negative affect (Cornélissen et al. 2005). Pertinence may stem from the observation that JF and FT had no circadian and only a circaseptan feature in the self-ratings. For circaseptans in health, see Fig. 16.

in local time. Times of switches from CST to DST in the USA can be found online:

(http://aa.usno.navy.mil/faq/docs/daylighttime.php).

Another issue relates to the desirability to analyze data collected at intervals much shorter than one minute. This is the case for instance in electroencephalographic data, and also in records from magnetometers that typically use sampling rates higher than $1 \mathrm{~Hz}$ (Cornélissen et al. 2001). Coding for seconds and fractions of a second thus becomes necessary.

Chronomics aims at aligning time structures in biota with time structures in their environment, near and far, Figs 11 and 12. Some records of the natural physical environment go back several million years. Coding data in the cnyrmodahrmn format is no longer complete enough for such applications, and the option to code data directly in selected time units is desirable. Current programs convert the date and time format into hours from a given reference time. Coding for time directly in such converted time units, whether hours, years, centuries, or milliseconds, would provide greater flexibility. Current computer hardware and software allow convenient extension of the current cnyrmodahrmn format to cnyrmodahrmnsccs, where sc and cs stand for second 


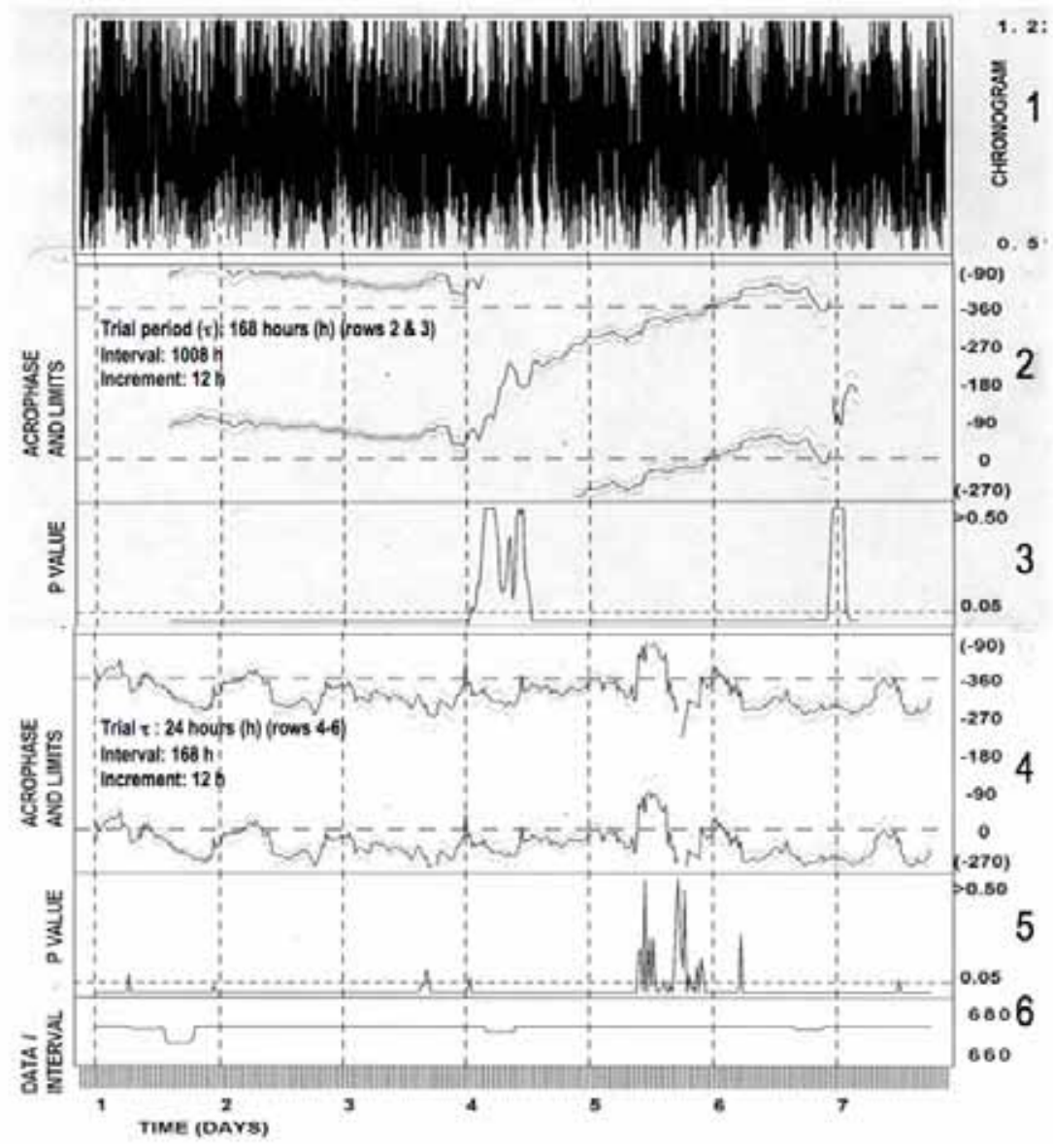

Fig. 15D. Horizontal component of the geomagnetic field, measured in Boulder, Colorado, USA, yields in analyses with the fit of a 7-day component (rows 2 and 3) an abrupt change in period at FM \#4, roughly coincident with the change in vigor ratings of the same component in JF and FT (Fig. 15C), with no change in length of the 24-hour component (bottom, row 4). Interestingly (not shown) all 3 components of the magnetic induction vector at Nain, Canada also undergo a change in period from $\sim 168$ hours to a period longer than 168 hours, as do those in Boulder.

and centisecond, still compatible with convenient time manipulation. Of course, we may need time more accurate than that, and more complicated program subroutines can be written.

Physical data collected from satellites or from different observatories on Earth are typically coded in universal time (UT). When comparing biological data with such physical data, it becomes important to have both kinds of data coded in a uniform way, hence the necessity to code data in such a way as to allow an easy and rapid conversion from local time to UT. A proposed solution to this problem is to add a code letter in front of the date and time to indicate the difference between local time and UT. An added one-character code on each line of data is needed, like in the blood pressure measurement example “ident,f,200908032340,120,70,60,", indicating that six hours need to be added to convert from Minnesota local time (CST) to UT. This coding can then be used either in commercial applications or in in-house software to convert data from local time to UT. Thus, the time information is present for comparing with cosmic influences.

The option to easily convert data coded in local time or in UT stems from their clear advantages in different kinds of analysis. Coding data in UT is the preferred choice for superposed epoch analyses in reference to space weather, whereas coding data in local time is recommended for spectral analysis, including least squares spectral analysis by cosinor, applicable to non-equidistant data. 


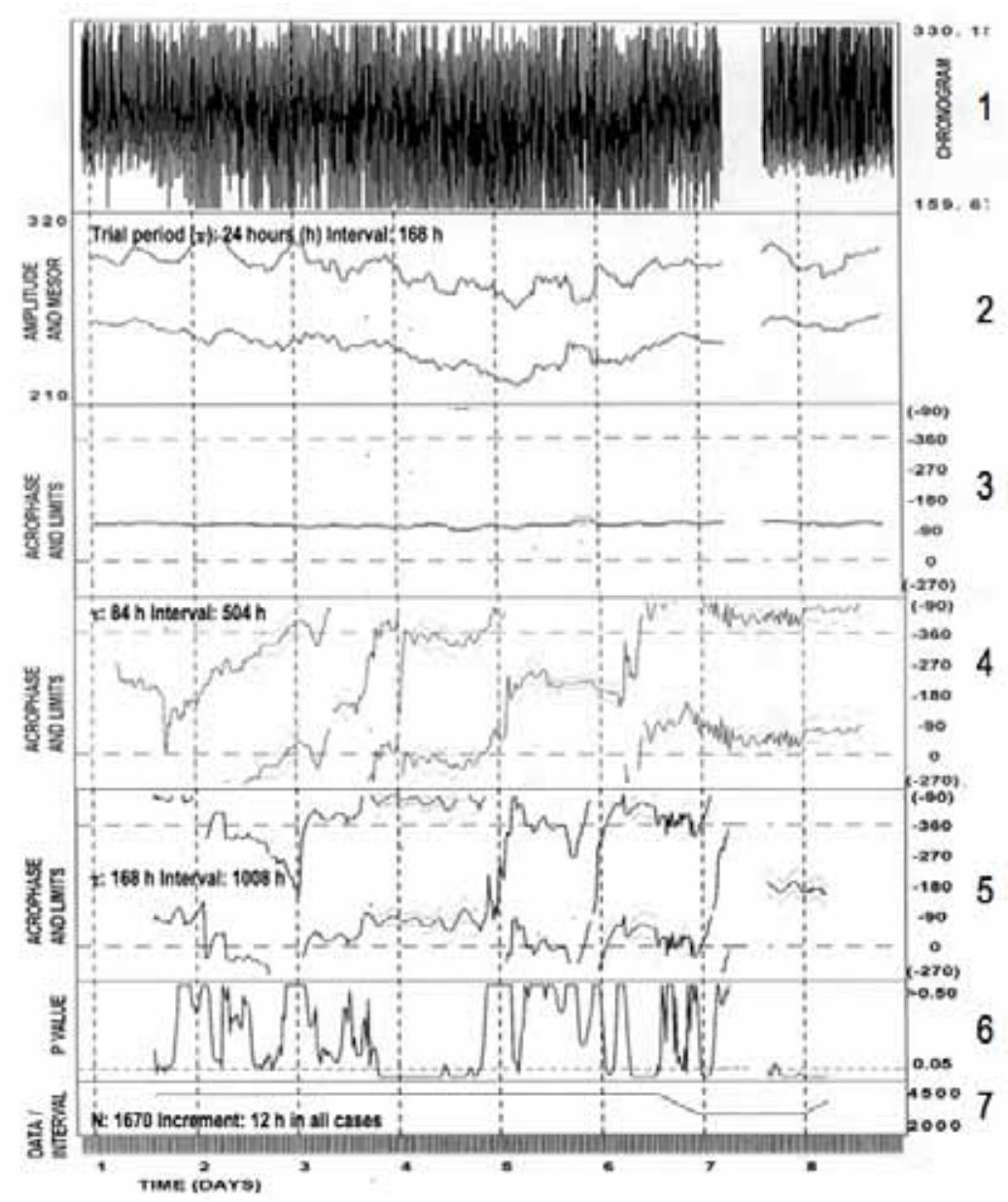

Fig. 15E. Thickness of the F2 layer of the ionosphere, with a statistically significant 24-hour component, showing no change in its acrophase, whereas the record lacks 84-hour and 168-hour components in the first 3 lunar cycles investigated, showing first a statistically significant 84-hour and 168-hour component around FM \#4.

\section{DISCUSSION}

When "circadian" was coined around 1950, it was dubbed "Halberg's paranoia" by a well-meaning friend. One had to be mentally unstable, so the thinking went, to measure every 4 hours temperatures around the clock in blinded and sham-operated mice in order to track built-in $\tau$ s of $\sim 24$ hours (Halberg et al. 2003). FH then lost his lab. Tracking the sun by collecting data for decades (that also allow one to recognize a high risk of stroke) (Halberg et al. 2009b) and looking at a new chapter of social disease may sound equally far-fetched. But we first need to better understand any deleterious effects of the sun to find appropriate measures to prevent social disease before countermeasures can be developed that correspond to a need, less obvious, but perhaps not less important, than that for the case of heating and air-conditioning, to cope with cold and hot temperatures. Monitoring BP and HR for stroke prevention may help that added purpose as well. The method for testing whether a proportion of congruence is a matter of chance, developed by Patricia Grambsch, is noteworthy. When she used it to check the statistical significance of the congruence between systolic BP and the solar wind's speed, she found the association significant $(\mathrm{P}<0.05)$. Her approach showed the long sought statistical significance of solar congruences with mental functions, that may also contribute a solar aspect to suicide (Table 2, cf. Halberg et al. 2008a), already recognized in 1938 by Düll and Düll (1938), Fig. 13, albeit without inferential statistical considerations and without detection of a spectral difference between genders.

Mechanisms putatively underlying influences from space weather on variables such as suicides may 


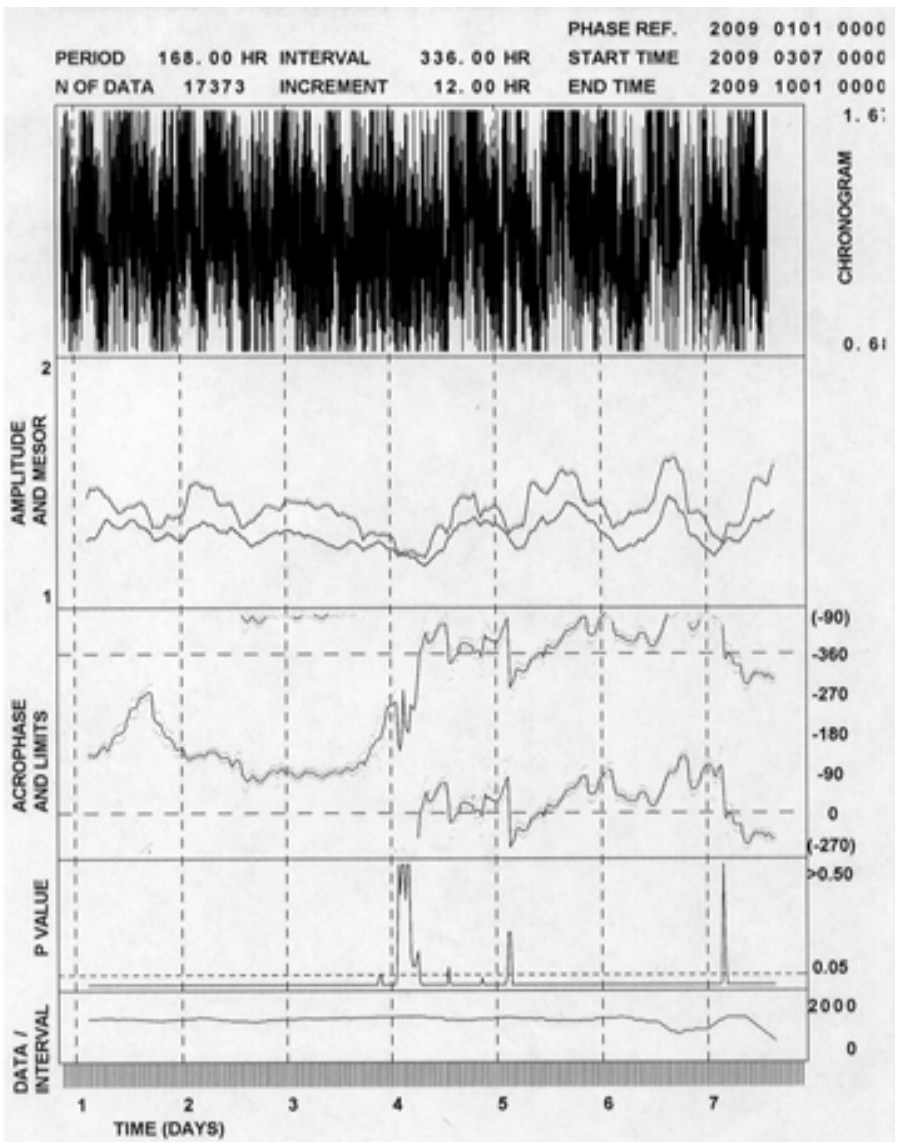

Fig. 15F. Circaseptan pattern in solar wind speed abruptly altered after vertical dashed line \#4 (vertical dashed lines correspond to times of full moon).

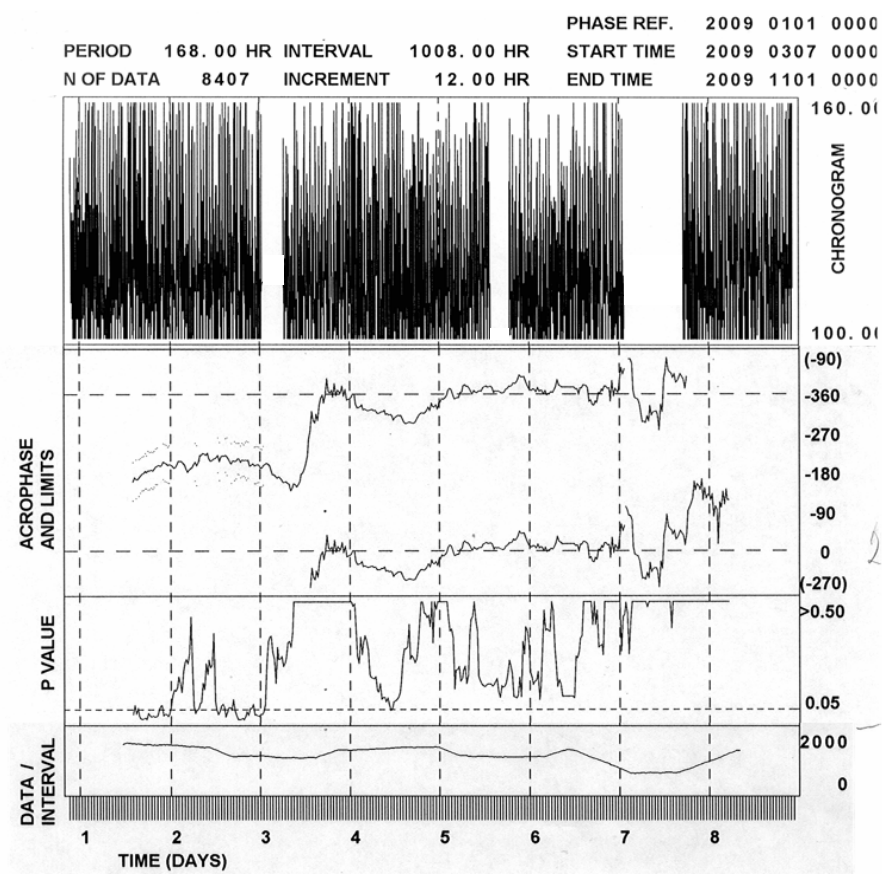

Fig. 16A. The clipped SBP data in the top row are those of a woman (GC) of about the same age as JF. The time course of the circaseptan acrophase is shown in the second row. It reaches statistical significance only transiently, mostly during the first 
two lunar cycles (vertical dashed lines indicate full moons), as seen from the P-values displayed in the third row (the horizontal dashed line corresponds to $\mathrm{P}=0.05$ ). The data of JF and FT during the same span show a much more consistent circaseptan rhythm. A phase jump is suggested after the third full moon, apparently not accompanied by desynchronization from the precise week.

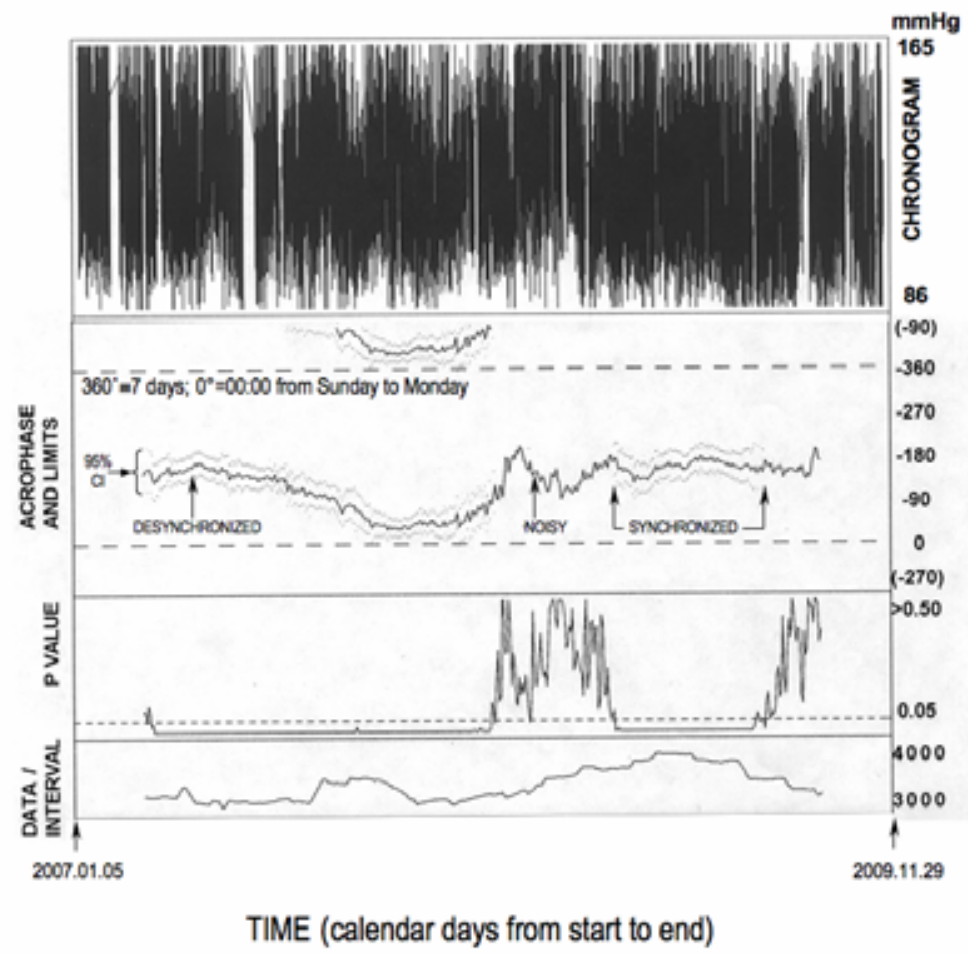

Fig. 16B. Alternating 7-day synchronized and desynchronized (or noisy) behavior of circaseptan rhythm in systolic blood pressure (SBP, clipped, top row), automatically measured at 30-minute intervals with few gaps by FH, a man 88 years old at the start of the record. A 168-hour (7-day) cosine curve was fitted to 168-day (4,032-hour) sections displaced by increments of 48 hours. The series of 21,056 SBP measurements covers the span from 5 January 2007 to 29 November 2009. The acrophase, $\Phi$, the peak of the cosine function best approximating all data, is shown in the second row, the dashed lines corresponding to $0^{\circ}$ or $360^{\circ}$, with a double plot when the $\Phi$ nears the zero line. A horizontal time course of the $\Phi$ s implies synchronization with the societal 7-day week. It is found, e.g., at the beginning of the record when the zero-amplitude assumption is rejected, as is apparent from the third row of P-values, in which the horizontal dashed line denotes statistical significance at the level $2 \alpha=0.05$. Dots bracketing the $\Phi$ s represent $95 \%$ CIs. After a horizontal trajectory, the $\Phi$ s gradually advance to a point when statistical significance is lost. The advance in $\Phi$ is compatible with a circaseptan desynchronization from the societal 7-day week. A span of noise follows after the middle of the record, and is followed in turn by the reappearance of a statistically significant 7-day synchronized rhythm, which toward the end of the record is again noisy. If the interval for analyses is shortened and the analysis is restricted to the span investigated in JF and FT, the $\Phi$ s advance, so that the behavior differs from that found in JF and FT. It is commonly mistakenly assumed that weekly changes in organisms are purely societal, thoroughly documented evidence to the contrary notwithstanding. First, a circaseptan rhythm in the excretion of 17-ketosteroids desynchronized from the calendar week after androgen drug administration, while urine volume continued to cycle with a precise weekly schedule (Halberg et al. 1965). Second, circaseptan desynchronization was found in a eukaryotic unicell's electric potential in continuous light (Halberg et al. 2001b). It is not unusual for members of a magnetolabile family (Fig. 15C). 
Halberg et al.: Personalized chronobiologic cybercare

Table 2: Near-transyears replace calendar-year component in pattern of suicides by women in Minnesota's mid-continental climate*.

\begin{tabular}{lccc}
\hline Trial period (years) & Gender & Period (years) [CI $]$ & Amplitude [CI $]$ \\
\hline \multirow{2}{*}{1} & $\mathrm{~F}$ & $1.020\left[\mathbf{1 . 0 0 3 , \mathbf { 1 . 0 3 7 } ] ^ { * * }}\right.$ & $0.03[+0.00,0.05]$ \\
& $\mathrm{M}$ & $1.002[0.984,1.020]$ & $0.05[+0.00,0.09]$ \\
1.05 & $\mathrm{~F}$ & $1.073[1.057,1.089]^{* *}$ & $0.03[+0.00,0.05]$ \\
& $\mathrm{M}$ & - & - \\
1.35 & $\mathrm{~F}$ & $1.428[1.389,1.467]^{* * *}$ & $0.02[+0.00,0.04]$ \\
& $\mathrm{M}$ & $1.276[1.252,1.300]^{* * *}$ & $0.06[0.01,0.10]$ \\
\hline
\end{tabular}

*As assessed by the linear-nonlinear cosinor (Refinetti et al. 2007). The pattern of the extreme depression of suicide by the time of death in 1979-2007 suggests that women are more sensitive than men to unseen particle radiation from the sun (probably to heliomagnetics). Changes with the seasons in light and temperature leave a signature in men, as reported overall earlier (Halberg 1973).

Note that the calendar-year period used as initial value converged to a period in men compatible with a 1-year synchronized component, since its CI (95\% confidence interval) overlaps 1.00 year. This is not the case in women committing suicide who are characterized by a near-transyear $(1.00$ year $<[\tau-\mathrm{CI}]<[\tau+\mathrm{CI}]<1.20$ years) with a CI not overlapping the precise year. A second near-transyear is suggested since a 1.05-year initial value converges to a 1.073-year component different from the 1.020 -year component resulting from the 1.0-year initial value. A far-transyear $(1.2$ years $\leq[\tau-\mathrm{CI}]<[\tau+\mathrm{CI}]<1.9$ years $)$ is also seen, differing in period again between men and women, but not in amplitude. **Near-transyear. ***Far-transyear.

While a far-transyear, but no near-transyear components, coexist with the calendar-year component in men's suicide incidence pattern in Minnesota, women show no calendar-year component, a different far-transyear and two transyear components. A presumably solar para-semiannual component is also documented in the spectrum of suicides of women, but not in men, in Australia

perhaps be investigated by studying gender differences in the time structure of their occurrence, sex hormones likely playing an important role. Such gender differences have been detected in a 29-year record of daily numbers of suicides in Minnesota, Table 2 (cf. Halberg et al. 2008a).

Seneca the Younger (5 BC-65 AD) is credited with suggesting that "It is not because things are difficult that we do not dare; it is because we do not dare that they are difficult". There is no alternative to replacing a spotcheck medicine by one of self-surveillance. Some new functional instrumentation has proved to be indispensable for a reliable diagnosis of VVDs, and can be rendered yet more affordable and less obtrusive. In using it, we may do more than stroke prevention: we may find ways to prevent figurative infections of the mind. Time may tell if we hurry, or we follow the example of prior civilizations, our noosphere notwithstanding.

\section{CONCLUSION}

As a dividend from monitoring BP and HR for stroke and other severe disease prevention, the individuals and their investigators may themselves gain new insight into mechanisms underlying the influence of environmental factors on biota, while avoiding possible blunders and controversy, and meta-analysts would also be served. Early work that led to the field of chronobiology revealed the critical importance of stating the schedules of lighting, rest-activity, sleep-wakefulness, feeding and the clock hour(s) at which an investigation was carried out. Failure to do so can yield highly statistically significant intra- or inter-individual differences in opposite directions for person(s) compared at different times.

It is within the mandate of editors of scientific journals to insist on temporal and spatial coding of the results obtained from any investigation in time. Properly coded data can be made available to chronometa-analyses that may forestall the unavoidable blunders that occur if, e.g., data obtained for decades in the morning yield results opposite to those in the evening, Fig. 10 (Halberg et al. 2008g). Precisely because space weather influences human affairs along several frequencies, the mapping of the corresponding spectrum constitutes the indispensable control in any human investigation as a function of time. The mapping of the biosphere matches in 
importance physicists' mapping of helio- and geomagnetics, among many other aspects of space weather, and the aligned mapping and interpretation of results may lead to a mutually validating unified science.

\section{EPILOGUE}

Students of chronomics, notably if they are health care workers, need to multitask, like a physician who jumps into the lake to save a drowning man. He sees a woman drowning and saves her as well, and then sees two more people drowning. He also sees a thoughtful scientist on the shore and asks the scientist to save one of the drowning people while he, the physician, gets the other. The pensive scientist refuses because (this is how a molecular biologist tells the story) he wants to find out who is throwing the people into the lake. This is his view. The people may all be entering the lake without anybody throwing them in, simply because they are the blind being led by the blind. This is the status quo of those who accept the concept of a time-invariant BP and HR. Chronobiologic physicians must multitask: save as many of those near them as they can; and help by contributing the data to an educative, analytic and investigative website, so that we eventually find the proximate causes of problems of figurative "drowning" in the form of afebrile asymptomatic disease risk syndromes, VVDs and VVSs (Vascular Variability Syndromes, when two or more VVDs coexist). We must concurrently remove all reasons for a problem, including the reeducation of those who may currently lead, albeit not throw people into the lake, and if one cannot teach them, give "swimming" lessons as part of a general (chronobiologic and chronobioethical) education. There is no alternative but to abandon blind "leaders" who rely on spotchecks, that includes the 1- or 2-day (too short) ABPM. Omnia metire quaecumque licet et immensa ad mensuram tempestive et ergo significative redige.

Findings in 1,677 titles since 1989, along with a complete bibliography of $\mathrm{FH}$, dating back to 1946 , are available on two websites (http://www.msi.umn.edu/ halberg/, and downloadable from the World Organization of Scientific Cooperation SWB at http://www.franz-halberg.wosco.org/list_of publications.html). Selected papers can also be downloaded from both websites (e.g., see http://www.franz-halberg.wosco.org/publications.ht $\mathrm{ml}$ ). A diploma from WOSCO is posted at http://wosco.org/index.shtml?id_file=99\&id_node=
1154, with a medal from the International Academy of Science H\&E, suggesting a trend toward a unified transdisciplinary science, supported by another medal for contributions to geosciences from the Schmidt Institute of the Physics of the Earth in Moscow. Greetings in English from Russian colleagues are posted on http://chronobiology.ru.

\section{PERSPECTIVE}

The scope of the far-transyear periodicities noted for the incidence pattern of terrorism worldwide and reported earlier for the circulation of blood in an individual (Halberg et al. 2006a) was extended by Prof. Miroslav Mikulecký, emeritus head of the department of internal medicine at Comenius University, Bratislava, Slovakia. Mikulecký's publications, like ours, mirror one of the solar wind's wobbly periodicities, that he dubbed "Halberg's transyear" (Kováč and Mikulecký 2005, 2006, Mikulecký and Florida 2005, Mikulecký 2006). Moreover, by the use of cross-spectral multivariate coherence he concomitantly considers the relative contributions to human epilepsy of geomagnetism and gravitation, reporting on a primary role of the latter, a topic deserving follow-up with methods such as those he had used on appropriate time series relating to the elucidation of many other problems (Mikulecký 2007). We all stand on the shoulders of many others (Ertel 1994, 1996, 1997a, b), including some who did not pursue the uncertainties of cycles involved (Dewey and Mandino 1971) or ignored the cycles (Stoupel et al. 2000, 2003) rather than assessing their ever-present uncertainties to avoid correlations that signify no more than concurrent cyclicities. The vast literature that had accumulated by 1938 was scholarly reviewed by Düll and Düll (1938); Alexander Leonidovich Chizhevsky (1934, 1971, cf. Sigel 1979, Halberg et al. 2001c) and Harlan True Stetson (1947) foresaw it all. Mikulecký (1990) gathered objective evidence and organizing meetings (Mikulecký 1993, 1994, 1997) focused on the moon. A putatively lunar signature of the double tidal wave (Doodson 1921) characterizes the self-ratings of a 61-year-old woman and her 42-year-old daughter (Halberg et al. 2009f), as seen in Figs 14 and $15 \mathrm{~A}-\mathrm{F}$, our current challenge. Results from a clinically healthy woman and from a clinically healthy man monitored during the same span serve as controls, Figs 16A-B. Can a putatively magnetolabile family serve itself and science by thorough self-observation, yet with help from the biomedical community? An answer may relate to a concern for all of us. 


\section{ACKNOWLEDGEMENT}

To implement the vision of pioneers, we followed Sir Norman Lockyer (1874) in the past, and trust that others, with us, will follow him in the future: "Surely in Meteorology, as in Astronomy (we add, in a unified science), the thing to hunt down is a cycle (emphasis ours), and if that is not to be found in the temperate zone, then go to the frigid zones (as one of us, GC, did: Cornélissen et al. 2001, our insert) or to the torrid zone (as Mikulecký did: Mikulecký and Florida, 2005, our insert) to look for it, and if found, then above all things, and in whatever manner, lay hold of, study it, record it and see what it means" (read: chronomics; our insert).

\section{SUPPORT}

GM-13981 (FH) and University of Minnesota Supercomputing Institute (GC, FH).

\section{REFERENCES}

Baumjohann W, Haerendel G. Magnetospheric convection observed between 0600 and 1200 LT: solar wind and IMF dependence. J Geophys Res. 90: 6370-6378, 1985.

Bernard C. De la diversité des animaux soumis à l'expérimentation. De la variabilité des conditions organiques dans lesquelles ils s'offrent à l'expérimentateur. J Anat Physiol norm pathol homme anim. 2: 497-506, 1865.

Bittle CC, Jr., Molina DJ, Bartter FC. Salt sensitivity in essential hypertension as determined by the cosinor method. Hypertension. 7: 989-994, 1985.

Brown FA, Jr. A unified theory for biological rhythms. In Aschoff J (ed.): Biological Clocks, North-Holland Publishing Co., Amsterdam 1965a, pp. 231-261.

Brown FA, Jr. Propensity for lunar periodicity in hamsters and its significance for biological clock theories. Proc Soc Exp Biol Med. 120: 792-797, 1965 b.

Brückner E. Klimaschwankungen seit 1700 nebst Beobachtungen über die Klimaschwankungen der Diluvialzeit. E. Hölzel, Wien und Olmütz 1890. 324 pp. (Penck A, Hrsg. Geographische Abhandlungen, Band IV.).

Burch JB, Reif JB, Yost MG. Geomagnetic disturbances are associated with reduced nocturnal excretion of a melatonin metabolite in humans. Neurosci Lett. 266: 209-212, 1999.
Cambrosio A, Keating P. The disciplinary stake: the case of chronobiology. Soc Stud Sci. 13: 323-353, 1983.

Chizhevsky AL. Action de l'ionisation de l'atmosphère et de l'ionisation artificielle de l'air sur les organismes sains et les organismes malades. In Piéry M (ed.): Traité de Climatologie: Biologique et médicale, Tome premier, Masson et Cie, Paris 1934, pp. 662-673.

Chizhevsky (Tchijevsky) AL (de Smitt VP, transl. and condensed). Physical factors of the historical process. Cycles. 22: 11-27, 1971.

Cornélissen G, Kawasaki T, Uezono K, Delea C, Halberg F II. Blood pressure rhythms and salt. Ann Ist Super Sanità. 29: 667-677, 1993.

Cornélissen G, Halberg F, Wendt HW, Bingham C, Sothern RB, Haus E, Kleitman E, Kleitman N, Revilla MA, Revilla M, Jr., Breus TK, Pimenov $\mathrm{K}$, Grigoriev AE, Mitish MD, Yatsyk GV, Syutkina EV. Resonance of about-weekly human heart rate rhythm with solar activity change. Biologia (Bratisl). 51: 749-756, 1996.

Cornélissen G, Halberg F, Hawkins D, Otsuka K, Henke W. Individual assessment of antihypertensive response by self-starting cumulative sums. J Med Eng Technol. 21: 111-120, 1997.

Cornélissen G, Engebretson M, Johnson D, Otsuka K, Burioka N, Posch J, Halberg F. The week, inherited in neonatal human twins, found also in geomagnetic pulsations in isolated Antarctica. Biomed Pharmacother. 55 (Suppl. 1): 32s-50s, 2001.

Cornélissen G, Halberg F, Breus T, Syutkina EV, Baevsky R, Weydahl A, Watanabe Y, Otsuka K, Siegelová J, Fišer B, Bakken EE. Non-photic solar associations of heart rate variability and myocardial infarction. J Atmos Sol-Terr Phys. 64: 707-720, 2002.

Cornélissen G, Watson D, Mitsutake G, Fišer B, Siegelová J, Dušek J, Vohlídalová L, Svačinová $\mathrm{H}$, Halberg F. Mapping of circaseptan and circadian changes in mood. Scr Med (Brno). 78: 89-98, 2005.

Cornélissen G, Halberg F, Rostagno C, Otsuka K. A chronomic approach to cardiac arrhythmia and sudden cardiac death. Auton Nerv Syst. 44: 251-254, 2007.

Cornélissen G, Halberg F, Otsuka K, Singh RB. Separate cardiovascular disease risks: circadian hyper-amplitude-tension (CHAT) and an elevated pulse pressure. World Heart J. 1: 223-232, 2008a.

Cornélissen G, Tarquini R, Perfetto F, Otsuka K, Gigolashvili M, Halberg F. About 5-month cycle in human circulating melatonin: signature of 
weather in extraterrestrial space? Poster presentation, Fourth UN/ESA/NASA/JAXA Workshop on the International Heliophysical Year 2007 and Basic Space Science: "First Results from the International Heliophysical Year 2007", Sozopol, Bulgaria, June 2-6, 2008b.

Cornélissen G, Grambsch P, Sothern RB, Katinas G, Otsuka K, Halberg F. Congruent biospheric and solar-terrestrial cycles. J Appl Biomed., in press.

Dewey ER, Mandino O. Cycles: The Mysterious Forces That Trigger Events. Hawthorn, New York 1971, $211 \mathrm{pp}$.

Doodson AT. The harmonic development of the tide-generating potential. Proc R Soc Lond A Conta. 100: 305-329, 1921.

Düll B, Düll T. Erd- und Sonnenphysikalische Vorgänge in ihrer Bedeutung für Krankheits- und Todauslosung. Nosokomeion. 9: 103-120, 1938.

Egeson C. Egeson's Weather System of Sun-spot Causality: Being Original Researches in Solar and Terrestrial Meteorology. Turner \& Henderson, Sydney 1889, 63 pp.

Endo T, Honma S, Hashimoto S, Honma K. After-effect of entrainment on the period of human circadian system. Jpn J Physiol. 49: 425-430, 1999.

Ertel S. Influenza pandemics and sunspots - easing the controversy. Naturwissenschaften. 82: 308-310, 1994.

Ertel S: Space weather and revolutions: Chizhevsky's heliobiological claim scrutinized. Stud Psychol (Bratisl) 39:3-22, 1996.

Ertel S. Bursts of creativity and aberrant sunspot cycles. In Nyborg H (ed.): The Scientific Study of Human Nature: Tribute to Hans J. Eysenck at Eighty, Elsevier, Oxford 1997a, pp. 491-510.

Ertel S. Long waves in economic history: connection with solar activity. In Mikulecký M (ed.): Proc. Conf. Chronobiology \& Its Roots in the Cosmos, High Tatras, Slovakia, September 2-6, 1997, Slovak Medical Society; Bratislava 1997b.

Goldstein JS. "Crackpot" cyclic weather theories. In Long Cycles: Prosperity and War in the Modern Age. Yale University Press, New Haven 1988, pp. 59-60.

Halberg F. Chronobiology. Annu Rev Physiol. 31: 675-725, 1969.

Halberg F: Laboratory techniques and rhythmometry. In Mills JN (ed.): Biological Aspects of Circadian Rhythms. Plenum Press, London/New York 1973, pp. $1-26$.

Halberg F. Historical encounters between geophysics and biomedicine leading to the Cornélissen-series and chronoastrobiology. In Schröder W (ed.): Long- and Short-Term Variability in Sun's
History and Global Change, Science Edition, Bremen 2000, pp. 271-301.

Halberg F, Cornélissen G. International Womb-to-Tomb Chronome Initiative Group: Resolution from a meeting of the International Society for Research on Civilization Diseases and the Environment (New SIRMCE Confederation), Brussels, Belgium, March 17-18, 1995: Fairy tale or reality? Medtronic Chronobiology Seminar \#8, April 1995, 12 pp.

Halberg F, Barnum CP, Silber RH, Bittner JJ. 24-hour rhythms at several levels of integration in mice on different lighting regimens. Proc Soc Exp Biol. 97: 897-900, 1958.

Halberg F, Engeli M, Hamburger C, Hillman D. Spectral resolution of low-frequency, smallamplitude rhythms in excreted 17-ketosteroid; probable androgen induced circaseptan desychronization. Acta Endocrinol (Copenhagen). 50 (Suppl. 103): 5-54, 1965.

Halberg F, Nelson W, Runge WJ, Schmitt OH, Pitts GC, Tremor J, Reynolds OE. Plans for orbital study of rat biorhythms. Results of interest beyond the Biosatellite program. Space Life Sci. 2: 437-471, 1971.

Halberg F, Johnson EA, Nelson W, Runge W, Sothern R. Autorhythmometry - procedures for physiologic self-measurements and their analysis. Physiol Teach. 1: 1-11, 1972.

Halberg F, Breus TK, Cornélissen G, Bingham C, Hillman DC, Rigatuso J, Delmore P, Bakken E. International Womb-to-Tomb Chronome Initiative Group. Chronobiology in space. Keynote, $37^{\text {th }}$ Annu. Meet. Japan Soc. for Aerospace and Environmental Medicine, Nagoya, Japan, November 8-9, 1991. University of Minnesota/Medtronic Chronobiology Seminar Series1, Dec 1991, 21 pp.

Halberg F, Cornélissen G, Hillman DC, Bingham C, Halberg E, Guillaume F, Barnwell F, Wu JY, Wang ZR, Halberg FE, Holte J, Schmitt OH et al. Chronobiology in a moon-based chemical analysis and physiologic monitoring laboratory. In Ponnamperuma C, Gehrke CE (eds.): A Lunar-Based Chemical Laboratory (LBCAL). A. Deepak Publishing, Hampton 1992, pp. 161-203.

Halberg F, Cornélissen G, Katinas GS, Watanabe Y, Otsuka K, Maggioni C, Perfetto F, Tarquini R, Schwartzkopff O, Bakken EE. Feedsidewards: intermodulation (strictly) among time structures, chronomes, in and around us, and cosmo-vasculo-neuroimmunity. About ten-yearly changes: what Galileo missed and Schwabe found. In Conti A, Maestroni GJM, McCann SM, 
Sternberg EM, Lipton JM, Smith CC (eds.): Neuroimmunomodulation (Proc. $4^{\text {th }}$ Int. Cong. International Society for Neuroimmunomodulation, Lugano, Switzerland, September 29-October 2, 1999). Ann NY Acad Sci. 917: 348-376, 2000.

Halberg F, Cornélissen G, Conti A, Maestroni G, Maggioni C, Perfetto F, Salti R, Tarquini R, Katinas GS, Schwartzkopff O. The pineal gland and chronobiologic history: mind and spirit as feedsidewards in time structures for prehabilitation. In Bartsch C, Bartsch H, Blask DE, Cardinali DP, Hrushesky WJM, Mecke W (eds.): The Pineal Gland and Cancer: Neuroimmunoendocrine Mechanisms in Malignancy, Springer, Heidelberg 2001a, pp. 66-116.

Halberg F, Cornélissen G, Katinas G, Hillman D, Schwartzkopff O: Season's Appreciations 2000: Chronomics complement, among many other fields, genomics and proteomics. Neuro Endocrinol Lett. 22: 53-73, $2001 \mathrm{~b}$.

Halberg F, Cornélissen G, Otsuka K, Katinas G, SchwartzkopffO. Essays on chronomics spawned by transdisciplinary chronobiology: Witness in time: Earl Elmer Bakken. Neuro Endocrinol Lett. 22: 359-384, 2001c.

Halberg F, Cornélissen G, Otsuka K, Schwartzkopff O, Halberg J, Bakken EE. Chronomics. Biomed Pharmacother. 55 (Suppl. 1): 153s-190s, 2001d.

Halberg F, Cornélissen G, Katinas G, Syutkina EV, Sothern RB, Zaslavskaya R, Halberg Francine, Watanabe Y, Schwartzkopff O, Otsuka K, Tarquini R, Perfetto P, Siegelová J. Transdisciplinary unifying implications of circadian findings in the $1950 \mathrm{~s}$. J Circad Rhythms. 2003; 1: 2, 61 pp.

Halberg F, Cornélissen G, Regal P, Otsuka K, Wang ZR, Katinas GS, Siegelová J, Homolka P, Přikryl $\mathrm{P}$, Chibisov SM, Holley DC, Wendt HW et al. Chronoastrobiology: proposal, nine conferences, heliogeomagnetics, transyears, near-weeks, near-decades, phylogenetic and ontogenetic memories. Biomed Pharmacother. 58 (Suppl. 1): S150-S187, 2004a.

Halberg F, Otsuka K, Katinas G, Sonkowsky R, Regal P, Schwartzkopff O, Jozsa R, Olah A, Zeman M, Bakken EE, Cornélissen G. A chronomic tree of life: ontogenetic and phylogenetic 'memories' of primordial cycles keys to ethics. Biomed Pharmacother. 58 (Suppl. 1): S1-S11, 2004b.

Halberg F, Cornélissen G, Katinas G, Tvildiani L, Gigolashvili M, Janashia K, Toba T, Revilla M, Regal P, Sothern RB, Wendt HW, Wang ZR et al.
International BIOCOS Group. Chrono-biology's progress: season's appreciations 2004-2005. Part I. Time-, frequency-, phase-, variable-, individual-, age- and site-specific chronomics. J Appl Biomed. 4: 1-38, 2006a.

Halberg F, Cornélissen G, Katinas G, Tvildiani L, Gigolashvili M, Janashia K, Toba T, Revilla M, Regal P, Sothern RB, Wendt HW, Wang ZR et al. International BIOCOS Group. Chrono-biology's progress: season's appreciations 2004-2005. Part II. Chronomics for an immediately applicable biomedicine. J Appl Biomed. 4: 73-86, $2006 \mathrm{~b}$.

Halberg F, Cornélissen G, Schwartzkopff O, Katinas GS, Chibisov SM, Khalitskaya EV, Mitsutake G, Otsuka K, Scheving LA, Bakken EE. Chronometaanalysis: magnetic storm associated with a reduction in circadian amplitude of rhythm in corneal cell division. Proc. Intern. Conf. Frontiers of Biomedical Science: Chronobiology, Chengdu, China, September 24-26, 2006c, pp. 40-42.

Halberg F, Cornélissen G, Berk M, Dodd S, Henry M, Wetterberg L, Nolley E, Beaty L, Siegelová J, Fišer B, Wolff C. BIOCOS project. Solar signatures in Australian suicide incidence: gender differences in prominence of photic vs. nonphotic spectral components. In Halberg F, Kenner T, Fišer B, Siegelová J (eds.): Proc. Noninvasive Methods in Cardiology, Brno, Czech Republic, October 4-7, 2008a, pp. 44-62.

Halberg F, Cornélissen G, Czaplicki J, Prabhakaran Nayar SR, Siegelová J. Brückner-EgesonLockyer: (BEL) climate cycle in original Brückner's, Lockyer's and follow-up data. In Halberg F, Kenner T, Fišer B, Siegelová J (eds.): Proc. Noninvasive Methods in Cardiology, Brno, Czech Republic, October 4-7, 2008b, pp. 74-89.

Halberg F, Cornélissen G, Schwartzkopff O. Quo vadis chronomics 2008: Measuring variability in us, among us and around us. In Halberg F, Kenner T, Fišer B, Siegelová J (eds.): Proc. Noninvasive Methods in Cardiology, Brno, Czech Republic, October 4-7, 2008c, pp. 16-25.

Halberg F, Cornélissen G, Sothern RB, Katinas GS, Schwartzkopff O, Otsuka K. Cycles tipping the scale between death and survival (="life"). Prog Theor Phys. (Suppl.) 173: 153-181, 2008d.

Halberg F, Kenner T, Fišer B, Siegelová J (eds.). Proc. Noninvasive Methods in Cardiology, Brno, Czech Republic, October 4-7, 2008e, 304 pp.

Halberg F, Schwartzkopff O, Cornélissen G, Hardeland R, Wendt HW, Otsuka K, Mitsutake G, Katinas GS, Sothern RB, Wang ZR. Eine geographisch unterschiedliche transdisziplinäre "Relativität" verschiedener "Jahreszeiten". In 
Hardeland R (ed.): Sonderdruck aus Abhandlungen der Leibniz-Sozietät der Wissenschaften, Band 23: Facetten der Chronobiologie, Trafo Verlag, Berlin 2008f, pp. 187-283.

Halberg F, Sothern RB, Cornélissen G, Czaplicki J. Chronomics, human time estimation, and aging. Clin Interv Aging. 3: 749-760, 2008g.

Halberg F, Cornélissen G, Best WR. A transtridecadal BEL cycle in human blood pressure and body weight. In Halberg F, Kenner T, Fišer B, Siegelová J (eds.): Proc. Noninvasive Methods in Cardiology, Brno, Czech Republic, July 7-10, 2009a, pp. 257-270.

Halberg F, Cornélissen G, Otsuka K, Siegelová J, Fišer B, Dušek J, Homolka P, Sánchez de la Peña $\mathrm{S}$, Singh RB. BIOCOS project. Extended consensus on means and need to detect vascular variability disorders (VVDs) and vascular variability syndromes (VVSs). Leibniz-Online $\mathrm{Nr}$. 5, 2009b.

Halberg F, Cornélissen G, Sothern RB, Czaplicki J, Schwartzkopff O. 35-year climate cycle in heliogeophysics, psychophysiology, military politics, and economics. Geophys Processes Biosph. 8: 13-42, 2009c.

Halberg F, Cornélissen G, Wilson D, Singh RB, De Meester F, Watanabe Y, Khalilov E. Chronobiology and chronomics: detecting and applying the cycles of nature. Biologist. 56: 209-214, 2009d.

Halberg F, Kenner T, Fišer B, Siegelová J (eds.). Proc. Noninvasive Methods in Cardiology 2009. Brno, Czech Republic, July 7-10, 2009e, 402 pp.

Halberg F, Kino T, Siegelová J, Homolka P, Finley J, Cornélissen G, Dušek J, Fišer B. Amplitude ratios of half-weekly vs. daily variability in diastolic blood pressure in putative magnetolability: with appendix. In Halberg F, Kenner T, Fišer B, Siegelová J (eds.): Proc. Noninvasive Methods in Cardiology, Brno, Czech Republic, July 7-10, 2009f, pp. 192-207.

Harman O, Dietrich MR (eds.). See section on Temin in Rebels, Mavericks, and Heretics in Biology. Yale University Press, New Haven and London, 2008.

Hayes DK, Halberg F, Cornélissen G, Shankaraiah K. Frequency response of the face fly, Musca autumnalis (Diptera: Muscidae), to lighting schedule shifts at varied intervals. Ann Entomol Soc Am. 79: 317-323, 1986.

Hillman D, Halberg F. Format for time-specified serial biologic data. Chronobiologia. 15:331-336, 1988.
Itoh K, Kawasaki T, Cugini P. Effects of timing of salt intake to 24-hour blood pressure and its circadian rhythm. J Nutr Sci Vitaminol (Tokyo). 40: 459-466, 1994.

Jozsa R, Halberg F, Cornélissen G, Zeman M, Kazsaki J, Csernus V, Katinas GS, Wendt HW, Schwartzkopff O, Stebelová K, Dulková K, Chibisov SM et al. Chronomics, neuroendocrine feedsidewards and the recording and consulting of nowcasts - forecasts of geomagnetics. Biomed Pharmacother. 59 (Suppl. 1): S24-S30, 2005.

Kenner T. An essay on some aspects of chronobiology: presented by an everyday-physiologist in honour of Franz Halberg. In Halberg F, Kenner T, Fišer B, Siegelová J (eds.): Proc. Noninvasive Methods in Cardiology, Brno, Czech Republic, July 7-10, 2009, pp. 318-324.

Kováč M, Mikulecký M. Secular rhythms and Halberg's paraseasonality in the time occurrence of cerebral stroke. Bratisl Med J. 106: 423-427, 2005.

Kováč M, Mikulecký M. Time sequence of epileptic attacks from the point of view of possible lunisolar connections. Intern. Conf. Frontiers of Biomedical Science: Chronobiology, Chengdu, China, September 24-26, 2006, pp. 175-179.

Kumar S, Mohan A, Sharma VK. Circadian dysfunction reduces lifespan in Drosophila melanogaster. Chronobiol Int. 22: 641-653, 2005.

Lockyer N. The thing to hunt down is a cycle. In Lockyer N: Contributions to Solar Physics. Macmillan, London 1874, pp. 424-425.

Lockyer WJS. The solar activity 1833-1900. Proc R Soc Lond. 68: 285-300, 1901.

Makarov VI, Sivaraman KR. New results concerning the global solar cycle. Sol Phys. 123: 367-380, 1989.

Marquardt DW. An algorithm for least-squares estimation of nonlinear parameters. SIAM J Appl Math. 11: 431-441, 1963.

Mikulecký M. Paroxysmal tachyarrhythmia and moon. Chronobiologia. 17: 71-73, 1990.

Mikulecký M. Reanalysis of natality in South Brazil. Halberg's paraseasonality dominating again. Intern. Conf. Frontiers of Biomedical Science: Chronobiology, Chengdu, China, September 24-26, 2006, pp. 187-188.

Mikulecký M. Solar activity, revolutions and cultural prime in the history of mankind. Neuro Endocrinol Lett. 28: 749-756, 2007.

Mikulecký M, Florida PL. Daily birth numbers in Davao, Philippines, 1993-2003: Halberg's transyear stronger than year. Abstr. $26^{\text {th }}$ Seminar, Man in His Terrestrial and Cosmic Environment, Úpice, Czech Republic, May 17-19, 2005. 
Mikulecký M (ed.). The Moon and Living Matter. Košice, Slovakia, September 23-25, 1993. Slovak Medical Society, Bratislava 1993, 97 pp.

Mikulecky M (ed.). Sun, Moon and Living Matter. Bratislava, Slovakia, June 28-July 1, 1994. Slovak Medical Society, Bratislava 1994, 159 pp.

Mikulecký M (ed.). Chronobiology \& Its Roots in the Cosmos. High Tatras, Slovakia, September 2-6, 1997. Slovak Medical Society, Bratislava 1997, 287 pp.

Millar JA, Lever AF, Burke V. Pulse pressure as a risk factor for cardiovascular events in the MRC Mild Hypertension Trial. J Hypertens. 17: 1065-1072, 1999.

Neugebauer M. Pioneers of space physics: A career in the solar wind. J Geophys Res. 102: 26887-26894, 1997.

Otsuka K, Cornélissen G, Halberg F. Predictive value of blood pressure dipping and swinging with regard to vascular disease risk. Clin Drug Invest. 11: 20-31, 1996.

Prabhakaran Nayar SR. Periodicities in solar activity and their signature in the terrestrial environment. ILWS Workshop, Goa, February 19-24, 2006, 9 pp.

Prestes A, Rigozo NR, Echer E, Vieira LEA. Spectral analysis of sunspot number and geomagnetic indices (1868-2001). J Atmosph Sol-Terr Phys. 68: 182-190, 2006.

Refinetti R, Cornélissen G, Halberg F. Procedures for numerical analysis of circadian rhythms. Biol Rhythm Res. 38: 275-325, 2007.

Rieger E, Share GH, Forrest DJ, Kanbach G, Reppin C, Chupp EL. A 154-day periodicity in the occurrence of hard solar flares? Nature. 312: 623-625, 1984.

Rostoker G, Fälthammar C-G. Relationship between changes in the interplanetary magnetic field and variations in the magnetic field at the earth's surface. J Geophys Res. 72: 5853-5863, 1967.

Sabine E. On periodical laws discoverable in the mean effects of the larger magnetic disturbances. No. II. Philos Trans R Soc Lond. 142: 103-124, 1852. See p. 121.

Schwabe H. Sonnen-Beobachtungen im Jahre 1843. Astron Nachr. 21 (no. 495): 254-256, 1844.

Sigel F. (Dreier W, Lerche D, Übers.; Göring H, Wissenschaftl. Red. der deutschsprachigen). Schuld ist die Sonne. Harri Deutsch, Thun/Frankfurt am Main 1979, 215 pp.

Silverman SM. Secular variation of the aurora for the past 500 years. Rev Geophys. 30: 333-351, 1992.

Sothern RB, Katinas GS, Cornélissen G, Halberg F. A 38-year record, albeit informative, is not yet enough: womb-to-tomb monitoring is overdue.
Appendix 2 of Halberg F, Cornélissen G, Regal P, Otsuka K, Wang ZR, Katinas GS, Siegelová J, Homolka P, Přikryl P, Chibisov SM, Holley DC, Wendt HW, Bingham C, Palm SL, Sonkowsky RP, Sothern RB, Pales E, Mikulecký M, Tarquini R, Perfetto F, Salti R, Maggioni C, Jozsa R, Konradov AA, Kharlitskaya EV, Revilla M, Wan CM, Herold M, Syutkina EV, Masalov AV, Faraone P, Singh RB, Singh RK, Kumar A, Singh R, Sundaram S, Sarabandi T, Pantaleoni GC, Watanabe Y, Kumagai Y, Gubin D, Uezono K, Olah A, Borer K, Kanabrocki EA, Bathina S, Haus E, Hillman D, SchwartzkopffO, Bakken EE, Zeman M: Chronoastrobiology: proposal, nine conferences, heliogeomagnetics, transyears, near-weeks, near-decades, phylogenetic and ontogenetic memories. Biomed Pharmacother. 58 (Suppl. 1): S179-S186, 2004.

Sothern RB, Katinas GS, Fišer B, Siegelová J, Cornélissen G, Halberg F. A transtridecadal cycle in human heart rate: Selective infradian, notably multidecadal solar-physiologic BEL congruences. In Halberg F, Kenner T, Fišer B, Siegelová J (eds.): Proc. Noninvasive Methods in Cardiology, Brno, Czech Republic, October 4-7, 2008, pp. 204-213.

Sothern RB, Cornélissen G, Yamamoto T, Takumi T, Halberg F. Time microscopy of circadian expression of cardiac clock gene mRNA transcription: chronodiagnostic and chronotherapeutic implications. Clin Ter. 160: e25-34, 2009.

Stehr N, von Storch H (eds.). (Stehr B, Gamlin G, transl.). Eduard Brückner: The Sources and Consequences of Climate Change and Climate Variability in Historical Times. Kluwer Academic Publishers, Dordrecht/Boston 2000, 338 pp.

Stetson HT. Sunspots in Action. Ronald Press Co., New York 1947, 252 pp.

Stoupel E, Israelevich P, Gabbay U, Abramson E, Petrauskiene J, Kalediene B, Domarkiene S, Sulkes J. Correlation of two levels of space proton flux with monthly distribution of deaths from cardiovascular disease and suicide. J Basic Clin Physiol Pharmacol. 11: 63-71, 2000.

Stoupel E, Petrauskiene J, Israelovich P, Habil, Abramson E, Sulkes J. Temporal distribution of death among oncology patients: environmental links. J Basic Clin Physiol Pharmacol. 14: 225-233, 2003.

Thiele ThN. De Macularum Solis antiquioribus quibusdam observationibus Hafniae institutis. Astron Nachr. 50: 259-261, 1859.

Watanabe Y, Cornélissen G, Halberg F, Beaty L, Siegelová J, Otsuka K, Bakken EE. Harm vs. 
benefit from losartan with hydrochlorothiazide at different circadian times in MESOR-hypertension or CHAT. In Halberg F, Kenner T, Fišer B, Siegelová J (eds.): Proc. Noninvasive Methods in Cardiology, Brno, Czech Republic, October 4-7, 2008, pp. 149-167.

Weydahl A, Sothern RB, Cornélissen G, Wetterberg L. Geomagnetic activity influences the melatonin secretion at latitude $70^{\circ} \mathrm{N}$. Biomed Pharmacother. 55: 57-62, 2001.
Wheeler RH. War 599 B.C.-1950 A.D. Indexes of International and Civil War Battles of the World. Foundation for the Study of Cycles, New York 1951, 15 pp.

Wolff CL. The rotational spectrum of g-modes in the sun. Astrophys J. 264: 667-676, 1983. 